\title{
The Effect of a Zero-Concentration Sink on Contaminant Transport and Remedial-Action Designs for the Weldon Spring Quarry, Weldon Spring, Missouri
}

by D. Tomasko

Environmental Assessment and Information Sciences Division, Argonne National Laboratory, 9700 South Cass Avenue, Argonne, Illinois 60439

April 1990

Work sponsored by United States Department of Energy,

Oak Ridge Operations Office, Oak Ridge, Tennessee 
NOMENCLATURE $\ldots \ldots \ldots \ldots \ldots \ldots \ldots \ldots \ldots \ldots \ldots \ldots \ldots \ldots \ldots \ldots \ldots \ldots \ldots$

FOREWORD $\ldots \ldots \ldots \ldots \ldots \ldots \ldots \ldots \ldots \ldots \ldots \ldots \ldots \ldots \ldots \ldots \ldots \ldots$

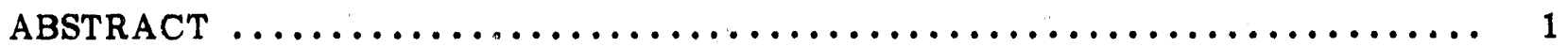

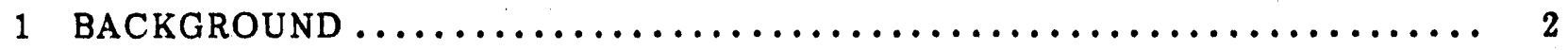

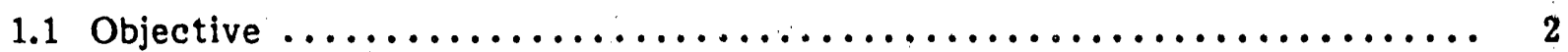

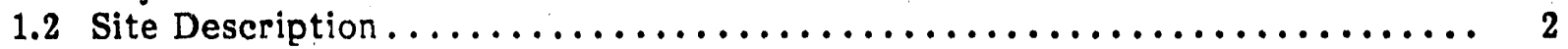

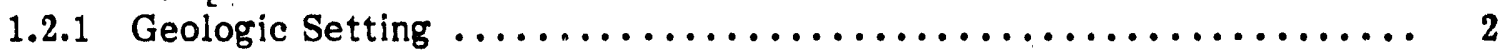

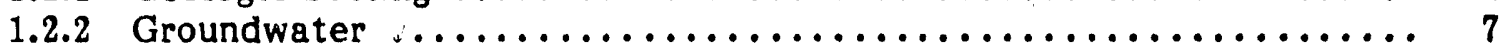

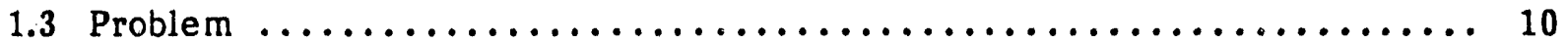

2 TRANSPORT MODEL $\ldots \ldots \ldots \ldots \ldots \ldots \ldots \ldots \ldots \ldots \ldots \ldots \ldots \ldots \ldots \ldots \ldots \ldots$

2.1 Theory: Natural Flow $\ldots \ldots \ldots \ldots \ldots \ldots \ldots \ldots \ldots \ldots \ldots \ldots \ldots \ldots \ldots \ldots \ldots$

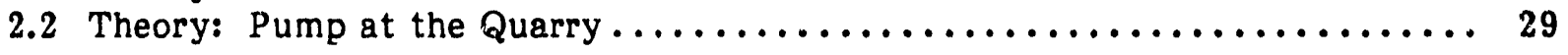

3 IMPLICATIONS FOR REMEDIAL-ACTION DESIGNS $\ldots \ldots \ldots \ldots \ldots \ldots \ldots \ldots \ldots$

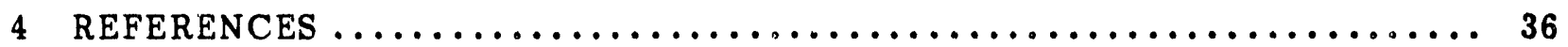

\section{FIGURES}

1.1 Location of the Weldon Spring Site, Weldon Spring, Missouri ........... 3

1.2 Surface-Water Features Near the Weldon Spring Quarry ............. 4

1.3 Generalized Stratigraphic Column $\ldots \ldots \ldots \ldots \ldots \ldots \ldots \ldots \ldots \ldots \ldots \ldots \ldots$

1.4 Idealized Geologic Cross Section for the Weldon Spring Quarry ......... 6

1.5 Water Levels Measured near the Weldon Spring Quarry in $1987 \ldots \ldots \ldots$

1.6 Groundwater Monitoring Locations at the Weldon Spring Quarry ......... 9

2.1 Concentration versus Distance for a Zero-Concentration

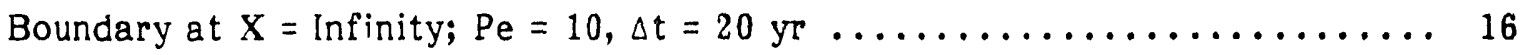

2.2 Concentration versus Distance for a Zero-Concentration

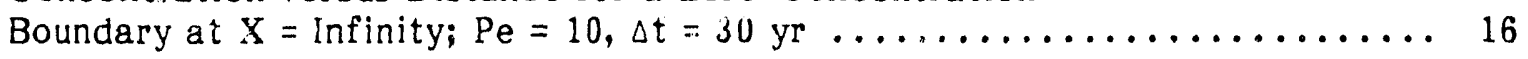

2.3 Longitudinal Contaminant Migration as a Function of Space and Time for a Zero-Concentration Boundary at $\mathrm{X}=$ Infinity;

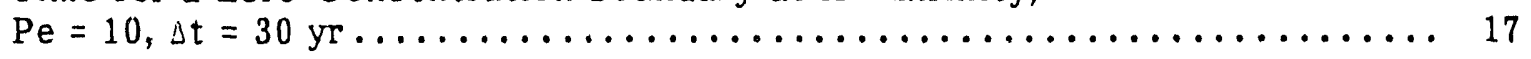

2.4 Reproduction of a Square-Wave Source Using the Stehfest Algorithm ...... 18 


\section{FIGURES (Cont'd)}

2.5 Concentration versus Time for a Zero-Concentration Sink at $X=1$

and $\mathrm{Pe}=10$, Using a Fourier Series Approach

2.6 Concentration versus Time for a Zero-Concentration Sink at $\mathrm{X}=1$

and $\mathrm{Pe}=5$, Using a Fourier Series Approach $\ldots \ldots \ldots \ldots \ldots \ldots \ldots \ldots \ldots$

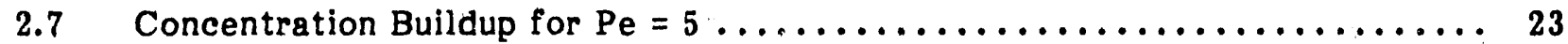

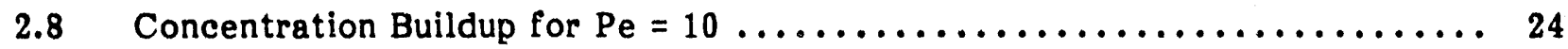

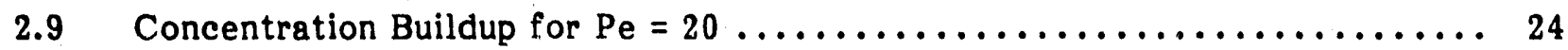

2.10 Steady-State Solutions for a Zero-Concentration Sink at $\mathrm{X}=1$

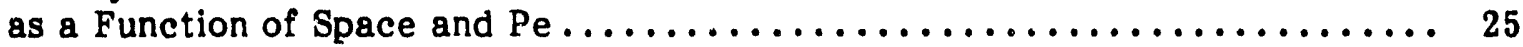

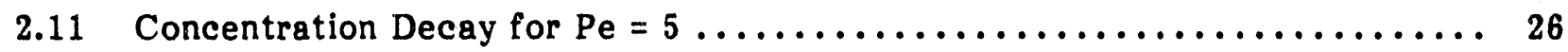

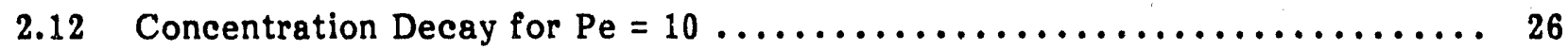

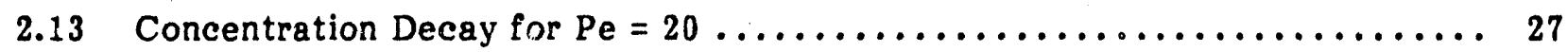

2.14 Comparison of Concentration versus Distance for Zero Boundary Conditions at $X=2500 \mathrm{ft}, 5000 \mathrm{ft}$, and Infinity at $1 \mathrm{yr}$;

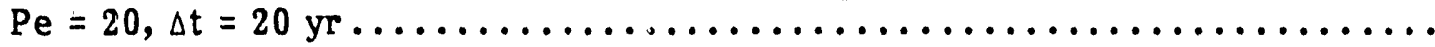

2.15 Comparison of Concentration versus Distance for Zero Boundary

Conditions at $X=2500 \mathrm{ft}, 5000 \mathrm{ft}$, and Infinity at $5 \mathrm{yr}$;

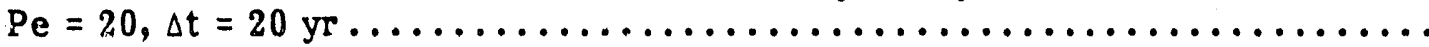

2.16 Comparison of Concentration versus Distance for Zero Boundary

Conditions at $X=2500 \mathrm{ft}, 5000 \mathrm{ft}$, and Infinity at $10 \mathrm{yr}$;

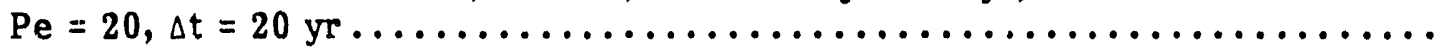

2.17 Comparison of Concentration versus Distance for Zero Boundary

Conditions at $\mathrm{X}=2500 \mathrm{ft}, 5000 \mathrm{ft}$, and Infinity at $20 \mathrm{yr}$;

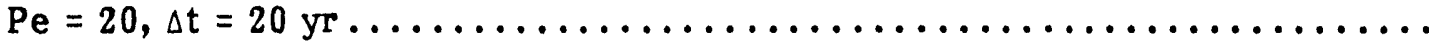

2.18 Pump-Back Concentrations as a Function of Space and Time for

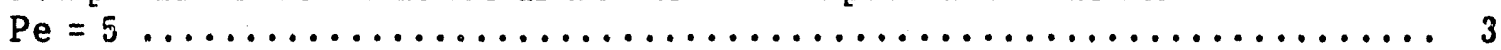

2.19 Pump-Back Concentrations as a Function of Space and Time for

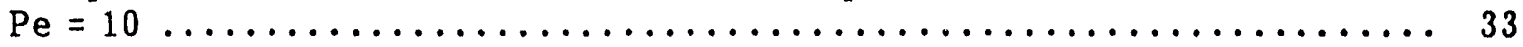

2.20 Pump-Back Concentrations as a Function of Time and Space for

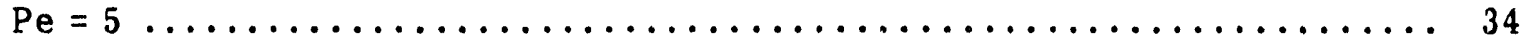

2.21 Pump-Back Concentrations as a Function of Time and Space for

$\mathrm{Pe}=10$ 


\section{NOMENCLATURE}

The following is a list of acronyms, initialisms, and abbreviations (including units of measure) used in this document.

\section{ACRONYMS, INITIALISMS, AND ABBREVIATIONS}

$\begin{array}{ll}\text { DOE } & \text { U.S. Department of Energy } \\ \text { EPA } & \text { U.S. Environmental Protection Agency } \\ \text { ERFC } & \text { complementary error function } \\ \text { ODE } & \text { ordinary differential equation } \\ \text { PCB } & \text { polychlorinated biphenyl } \\ \text { PDE } & \text { partial differential equation } \\ \text { Pe } & \text { Peclet number } \\ \text { TNT } & \text { trinitrotoluene }\end{array}$

\section{UNITS OF MEASURE}

$\begin{array}{ll}\mathrm{d} & \text { day(s) } \\ \mathrm{ft} & \text { foot (feet) } \\ \mathrm{km} & \text { kilometer(s) } \\ \mathrm{L} & \text { liter(s) } \\ \mathrm{m} & \text { meter(s) } \\ \mathrm{mi} & \text { mile(s) } \\ \mathrm{pCi} & \text { picocurie(s) } \\ \mathrm{yd} & \text { yard(s) } \\ \mathrm{yr} & \text { year(s) }\end{array}$




\section{FOREWORD}

The U.S. Department of Energy (DOE), under its Surplus Facilities Management Program, is responsible for conducting remedial actions at the Weldon Spring site, which is located about $48 \mathrm{~km}(30 \mathrm{mi})$ west of St. Louis in St. Charles County, Missouri. The site is included in the National Priorities List of the U.S. Environmental Protection Agrency (EPA). The Weldon Spring site became contaminated as a result of processing and disposal activities that took place frorn the 1940 s through the $1960 \mathrm{~s}$. The site consists of a quarry and a chemical plant area located about $6.4 \mathrm{~km}(4 \mathrm{mi})$ northeast of the quarry. The quarry is surrounded by the Weldon Spring Wildlife Area and is near a well field that constitutes a major source of potable water for St. Charles County; the nearest supply well is located about $0.8 \mathrm{~km}(0.5 \mathrm{mi})$ southeast of the quarry. From 1942 to 1969 , the quarry was used for the disposal of various radioactively and chemically contaminated materials. As part of overall site remediation, the DOE is proposing to conduct an interim remedial action at the quarry to manage the radioactively and chemically contaminated wastes.

The DOE's currently preferred alternative for managing these wastes is expeditious removal from the quarry with storage at the chemical plant area. Removai of the wastes will permit detailed characterization of the quarry subsurface; detailed characterization is necessary for evaluating the need for follow-up remediation. This

report presents the results of solute transport modeling, which will facilitate development of a conceptual hydrogeological model of the quarry area. The hydrogeological model will be useful for developing remedial action plans. 
THE EFFECT OF A ZERO-CONCENTRATION SINK ON CONTAMINANT TRANSPORT AND REMEDIAL-ACTION DESIGNS FOR THE WELDON SPRING QUARRY, WELDON SPRING, MISSOURI

by

David Tomasko

\begin{abstract}
One-dimensional analytical expressions are developed to simulate two processes in a homogeneous porous medium: (1) contaminant transport through a porous medium that has a zeroconcentration sink located at a finite distance from a step-function source; and (2) contaminant transport through a porous medium that has an initial steady-state distribution corresponding to a constant strength source and zero-concentration sink separated by a finite distance. For general applicability, the governing equations are cast in dimensionless form, making use of the flow system's Peclet number. Evaluation of the analytical expressions is accomplished by numerical inversion of Laplace-space concentrations using either a full Fourier series approach with acceleration, or the Stehfest algorithm; the method used depends on the presence or absence of abrupt discontinuities in the source term. The analytical expressions are used to evaluate possible contaminant conditions at the Weldon Spring quarry near Weldon Spring, Missouri. For the assumed conditions of the calculations and site-specific hydrogeological parameters, the following results have been found: contaminant concentrations should be at or near steady-state conditions; the spatial distribution of contaminants should be a function of the flow system's Peclet number; contaminant concentrations near the Femme Osage Slough, located approximately $213 \mathrm{~m}(700 \mathrm{ft})$ south of the quarry pond, should approach $z_{1} 0$; contaminant concertrations near the quarry during dewatering and bulk-waste removal should monotonically decrease with time; and the spatial distribution of contaminants during remedial activities should be relatively flat, especially near the dewatering pumps.

Future work will antail evaluating existing radionuclide or chemical concentration data to determine the applicability of the proposed contaminant transport model and to improve the hydrogeological conceptualization of the quarry area and vicinity.
\end{abstract}




\section{BACKGROUND}

\subsection{OBJECTIVE}

The U.S. Department of Energy (DOE) plans to perform a response action at the Weldon Spring quarry near St. Louis, Missouri (Fig. 1.1). Specific activities that are a part of this action can be divided into five areas: (1) removal and treatment of contaminated water from the quarry pond and other sources, (2) removal of existing bulk wastes, (3) potential removal of any residual materials remaining after bulk-waste removal, (4) potential restoration of the groundwater, and (5) potential restoration of surrounding properties. This report presents one-dimensional analytical solutions designed to investigate the potential effects of a zero-concentration sink at the Femme Osage Slough.

\subsection{SITE DESCRIPTION}

The Weldon Spring quarry is part of a DOE surplus facility located in St. Charles County, Missouri, appro: mately $6.4 \mathrm{~km}(4 \mathrm{mi})$ south of the Weldon Spring Chemical Plant and $48 \mathrm{~km}(30 \mathrm{mi})$ west of St. Louis (Fig. 1.1). The quarry is located near Route 94, about $213 \mathrm{~m}(700 \mathrm{ft})$ from the Femme Osage Slough. The quarry is $762 \mathrm{~m}(2500 \mathrm{ft})$ from the nearest well in the St. Charles municipal well field and $1.6 \mathrm{~km}(1 \mathrm{mi})$ from the Missouri River (Fig. 1.2). Originally the quarry was used to supply limestone and sand for construction. The nine-acre site was later used for disposal of soils and other materials contaminated with trinitrotoluene (TNT) during the 1940 s and 1950 s and the disposal of low-level radioactive wastes during the 1950 s and $1960 \mathrm{~s}$. The quarry is presently filled with about $72,637 \mathrm{~m}^{3}\left(95,000 \mathrm{yd}^{3}\right)$ of radioactively or chemically contaminated wastes, including steel drums, concrete and steel rubble, machinery, process residues, uncontained wastes, and contaminated soil.

\subsubsection{Geologic Setting}

The Weldon Spring quarry is located in low limestone hills near the west bank of the Missouri River. The mid-Ordovician bedrock of the quarry area is predominantly limestone and dolomite. In the vicinity of the quarry, the carbonate rocks dip to the northeast at a gradient of 11 to $15 \mathrm{~m} / \mathrm{km}$ (60 to $80 \mathrm{ft} / \mathrm{mi}$ ) (Berkeley Geosciences Associates 1984).

The bedrock is overlain in the upland areas by 3 to $18 \mathrm{~m}$ (10 to $40 \mathrm{ft}$ ) of silty clay derived primarily from glacial loess and till. Figure 1.3 shows a generalized stratigraphic column for the Weldon Spring site area; Fig. 1.4 shows an idealized geolngical crosssection for the quarry for a line passing through the quarry in a northwest to southeast direction. As indicated in Fig. 1.4, the walls of the quarry expose the Ordovician Kimmswick Formation, while the bedrock floor of the quarry, presently covered with debris, lies in the upper portion of the Decorah Formation. 


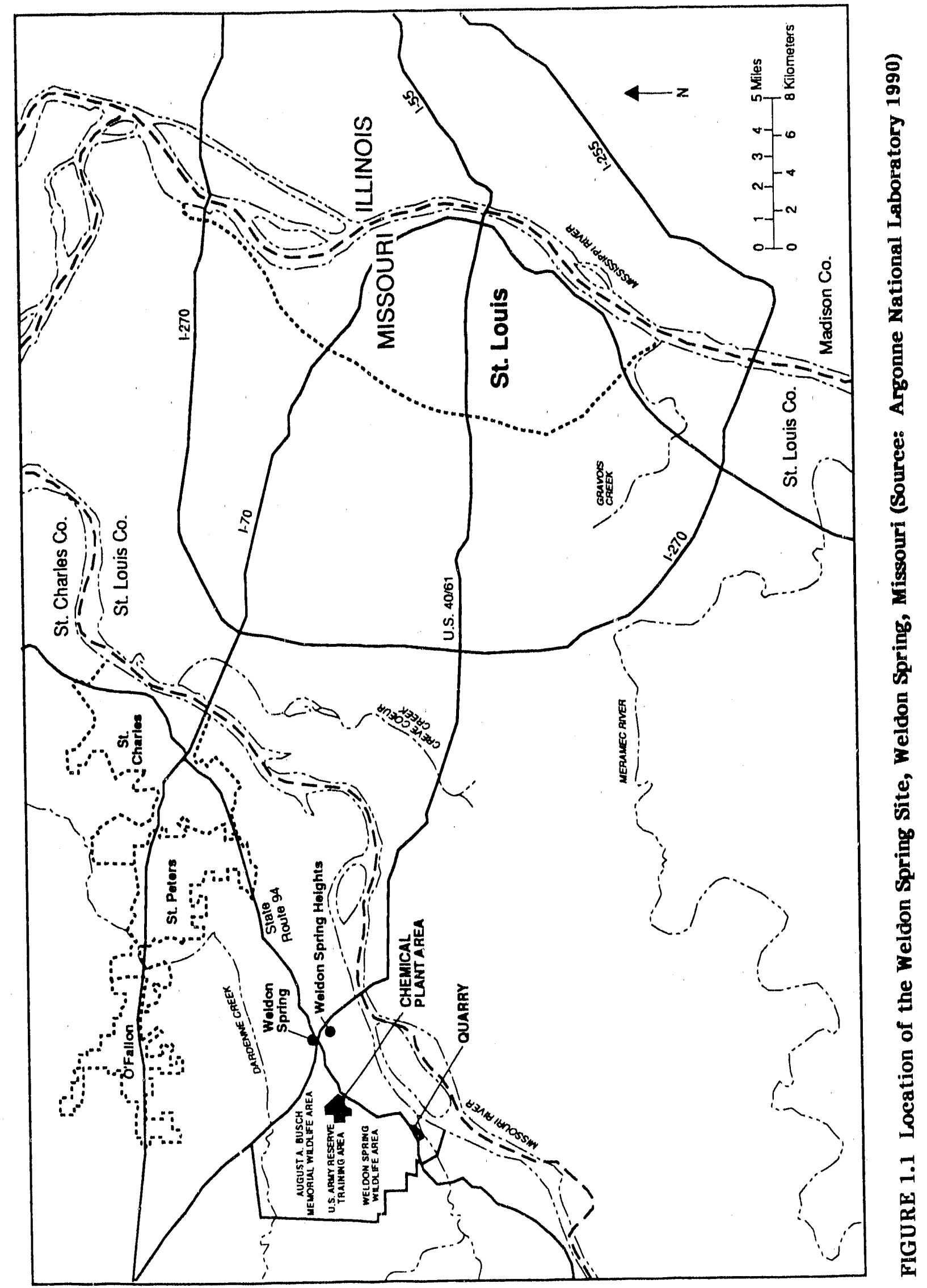




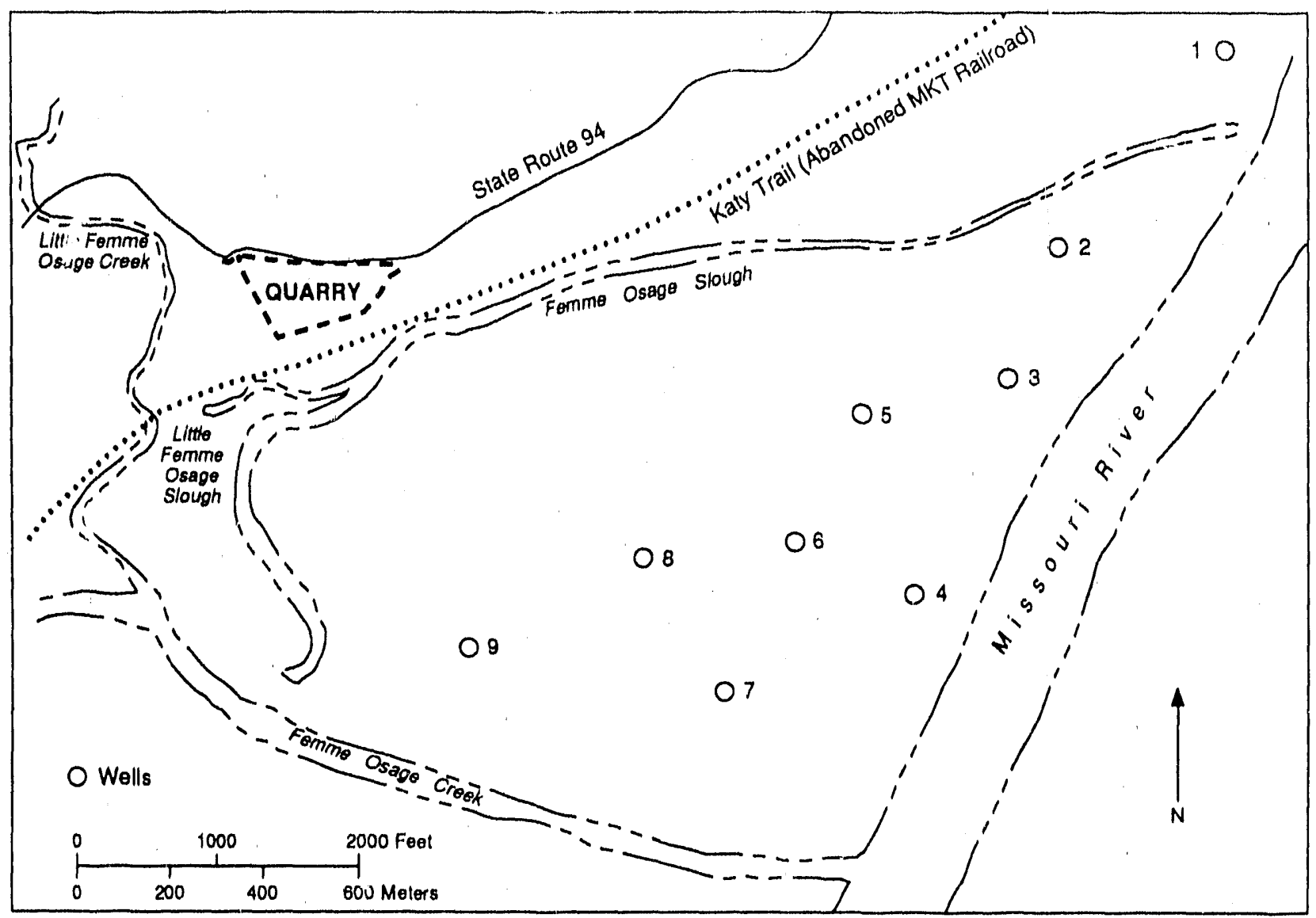

FIGURE 1.2 Surface-Water Features near the Weldon Spring Quarry (Source: Angonne National Laboratory 1990)

The Kimmswick Limestone, mined during quarry operation, is predominantly a crystalline limestone about $21 \mathrm{~m}(70 \mathrm{ft})$ thick. It is characterized by solution-enlarged features associated with the intersection of vertical joints and bedding planes.

The Decorah Formation is 6 to $12 \mathrm{~m}$ (20 to $40 \mathrm{ft}$ ) thick; its upper portion is predominantly composed of fossiliferous limestone with shaley partings (Berkeley Geosciences Associates 1984). The Decorah Formation contains shale beds and is considered to be a leaky confining layer on a regional scale (Kleeschulte et al, 1986). At the quarry, however, its confining capabilities may be limited by the presence of vertical joints and fractures and quarrying operations that penetrated the top $5 \mathrm{~m}(15 \mathrm{ft})$ of the formation (MK-Ferguson Company and Jacobs Engineering Group 1989). Underlying ic. Kimmswick and Decorah formations is the Plattin Formation, a thinly bedded, very fine crystalline, dolomitic limestone. Below the Plattin Limestone are the Ordovician Joachim Dolomite and the St. Peter Sandstone.

East and south of the quarry (Fig. 1.4), fine- to coarse-grained Quarternary alluvial deposits, sand, and gravels unconformably contact the Plattin, Decorah, and Kimmswick formations. Locally, the alluvium is composed of a surficial layer of $3 \mathrm{~m}$ 


\begin{tabular}{|c|c|c|c|c|c|c|c|c|c|c|c|c|c|c|c|c|c|c|c|c|}
\hline 总 & & & \multicolumn{5}{|c|}{ 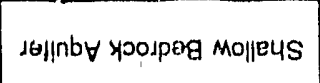 } & \multicolumn{5}{|c|}{ 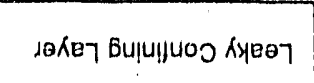 } & \multicolumn{8}{|c|}{ 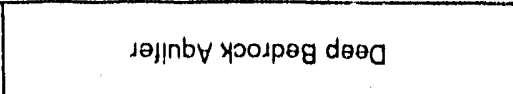 } \\
\hline 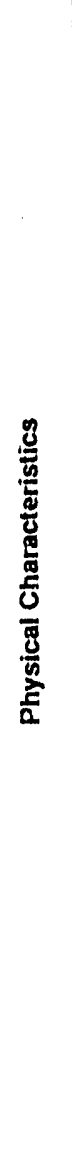 & 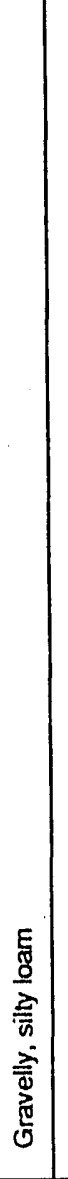 & 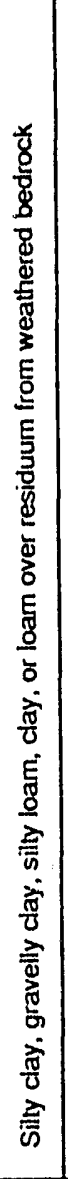 & 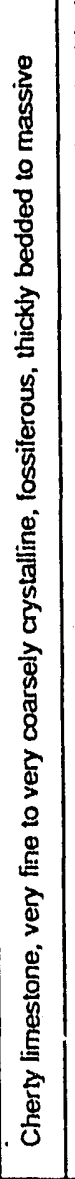 & 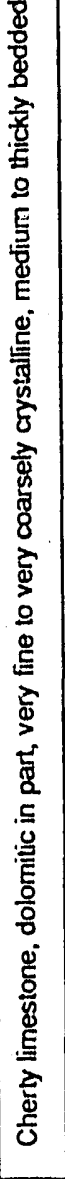 & 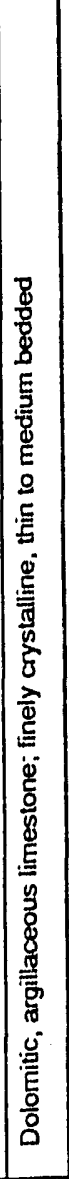 & 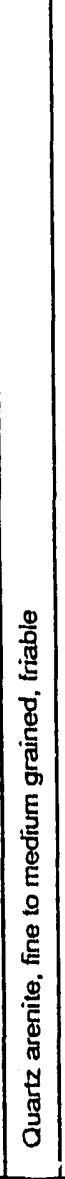 & 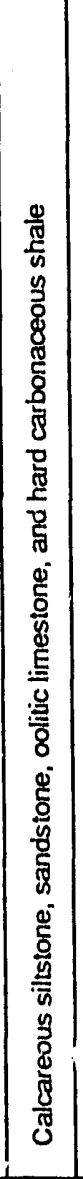 & 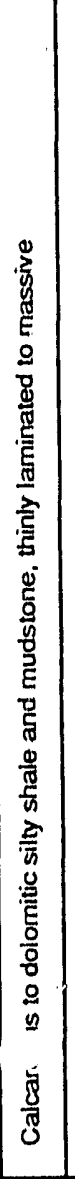 & 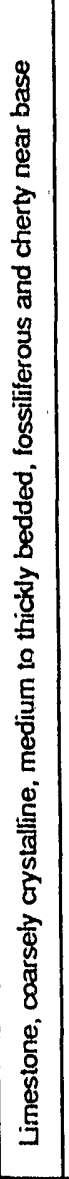 & 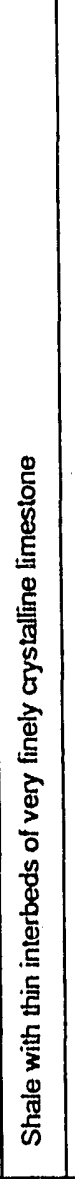 & 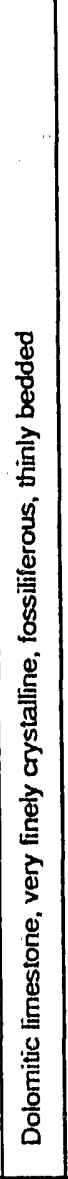 & 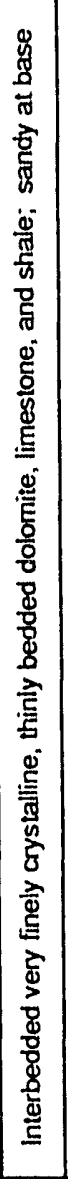 & 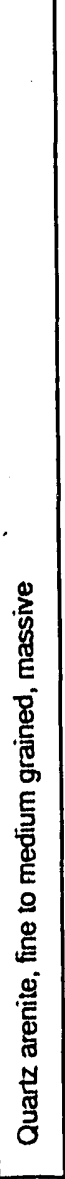 & 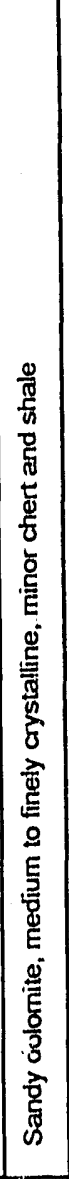 & 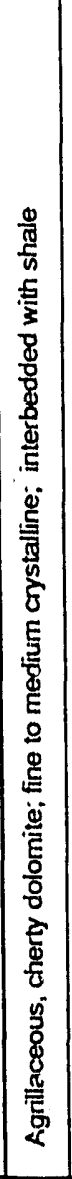 & 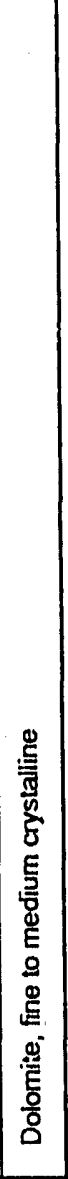 & 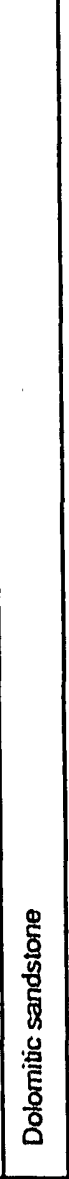 & 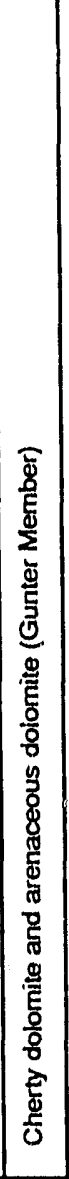 & 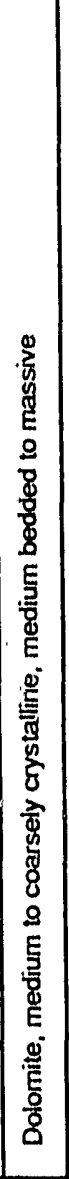 & 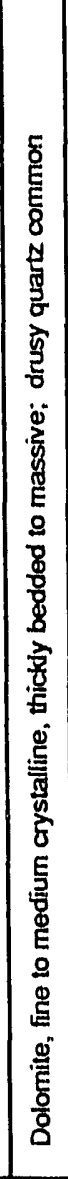 \\
\hline 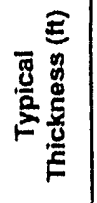 & 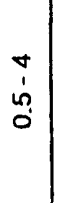 & 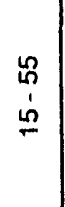 & \begin{tabular}{l}
8 \\
\multirow{2}{*}{} \\
1 \\
8 \\
\end{tabular} & $\begin{array}{l}? \\
? \\
i s\end{array}$ & $\begin{array}{l}0 \\
0 \\
1 \\
\dot{R} \\
\end{array}$ & & $\begin{array}{l}0 \\
0 \\
\vdots \\
q\end{array}$ & $\begin{array}{l}8 \\
1 \\
1 \\
0\end{array}$ & $\begin{array}{l}8 \\
\vdots \\
1\end{array}$ & $\begin{array}{l}8 \\
1 \\
\dot{e}\end{array} \mid$ & $\begin{array}{l}0 \\
\frac{9}{1} \\
\frac{8}{2}\end{array}$ & 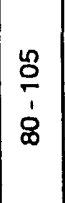 & 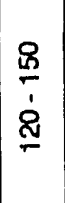 & $\begin{array}{l}8 \\
0 \\
\dot{8}\end{array}$ & 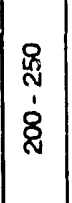 & 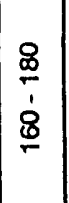 & $\mid \begin{array}{l}0 \\
\frac{1}{1} \\
\dot{8}\end{array}$ & 号 & \& & 8 \\
\hline 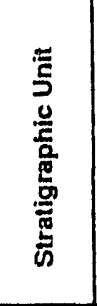 & 焉 & 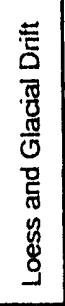 & 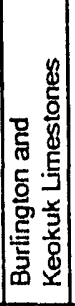 & 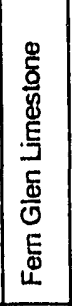 & 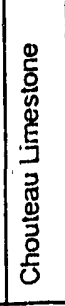 & & 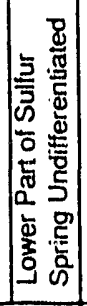 & 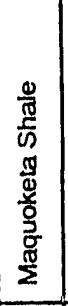 & 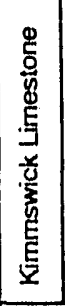 & 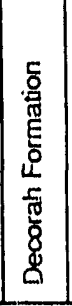 & 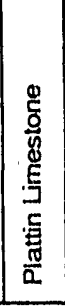 & 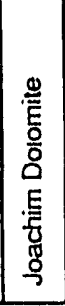 & 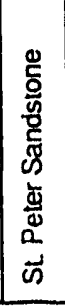 & 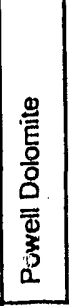 & 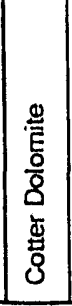 & 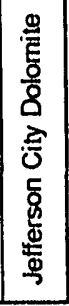 & 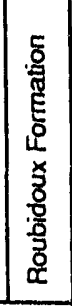 & 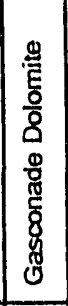 & 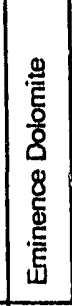 & 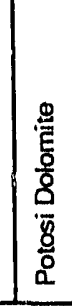 \\
\hline 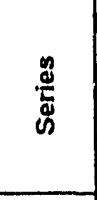 & $\begin{array}{l}0 \\
8 \\
8 \\
\frac{8}{1} \\
\end{array}$ & $\begin{array}{l}0 \\
\frac{0}{8} \\
\frac{8}{0} \\
\frac{.0}{0} \\
\frac{0}{0} \\
\end{array}$ & & 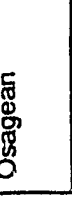 & 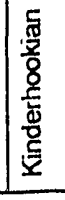 & & $\frac{0}{2}$ & 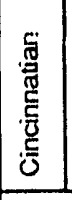 & & & 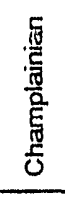 & & & & & 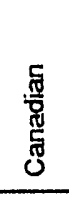 & & & & \\
\hline$\frac{\sqrt{5}}{0}$ & 0 & & & 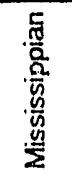 & & & 勇 & & & & & & 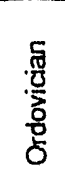 & & & & & & & 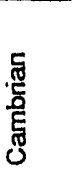 \\
\hline
\end{tabular}




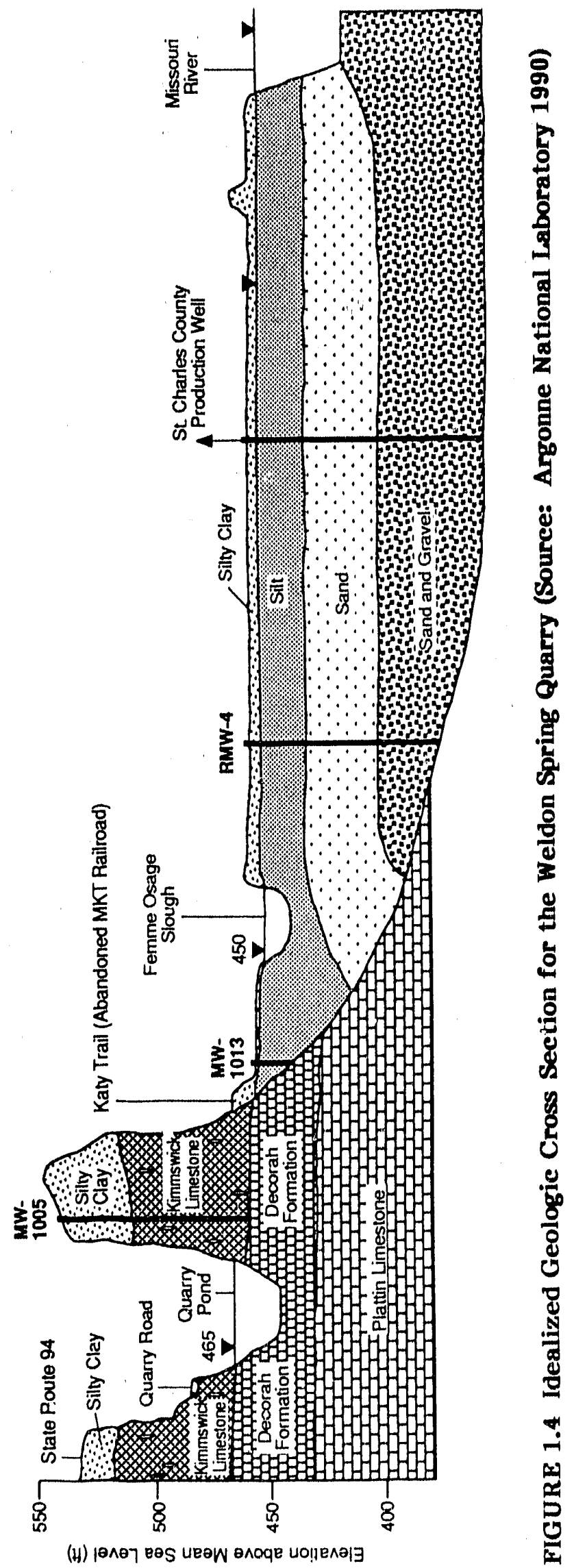


$(10 \mathrm{ft})$ of silt underlain by about $6 \mathrm{~m}(20 \mathrm{ft})$ of sand. The thickness of the silt layer increases toward the river. This water-bearing alluvium is a major contributor to the domestic water supplies of St. Charles County.

The alluvium north of the Femme Osage Slough consists of very fine-grained clays and silts of apparently low hydraulic conductivity and extends downward to the limestone bedrock. South of the slough, the alluvial aquifer becomes thicker and more permeable with correspondingly higher values of hydraulic conductivity and groundwater velocity (MK-Ferguson Company and Jacobs Engineering Group 1989).

\subsubsection{Groundwater}

Groundwater flow in the vicinity of the Weldon Spring quarry occurs in alluvium, fractured limestone and dolomite, and the St. Peter Sandstone (Berkeley Geosciences Associates 1984) (Fig. 1.3). Water-table conditions (1.e., unconfined aquifers) are typically found in areas of significant alluvial deposits; semiconfined conditions (confined to leaky aquifers) occur where layers of varying permeability are present. Flow in the limestone is primarily through secondary porosity provided by fractures and solution

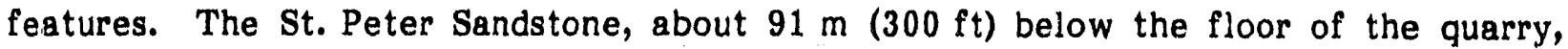
contains a confined groundwater aquifer. The degree of connection between the St. Peter Sandstone and the overlying formations is not fully understood.

In the vicinity of the quarry, groundwater flows primarily from north to south; however, water-level measurements taken in 1987 indicate a possible mounding of groundwater at the quarry due to local recharge from precipitation and surface runoff (MK-Ferguson Company and Jacobs Engineering Group 1989) (Fig. 1.5). Even with this local mounding feature, contaminated water from the quarry is expected to flow toward the Femme Osage Slough and St. Charles County municipal well fleld. The well field is completed in the alluvium near the Missouri River (Fig. 1.2). Near the quarry, flow is likely to take place through secondary porosity features in the fractured limestone formations. Near the well field, flow is through a porous Missouri River alluvium.

Groundwater flow in the alluvial aquifer near the Femme Osage Slough is not well defined (MK-Ferguson Company and Jacobs Engineering Group 1989). Groundwater levels in the bedrock consistently measure about $3 \mathrm{~m}(10 \mathrm{ft})$ higher than elevations in the alluvium near the slough. This abrupt change in water level at the interface of the two groundwater regimes indicates a poor hydraulic connection between the limestone bedrock aquifer and the alluvium.

Currently, 28 DOE monitoring wells are located at the Weldon Spring quarry and surrounding properties (Fig. 1.6). Eleven of these wells monitor bedrock water quality at and very near the quarry (MK-Ferguson Company and Jacobs Engineering Group 1989). The remaining monitoring wells (17) are completed in the alluvium/soils above the bedrock, south and east of the slough. In addition, four St. Charles County monitoring wells (RMW-1 through 4) completed in the alluvium are also monitored by the DOE. 


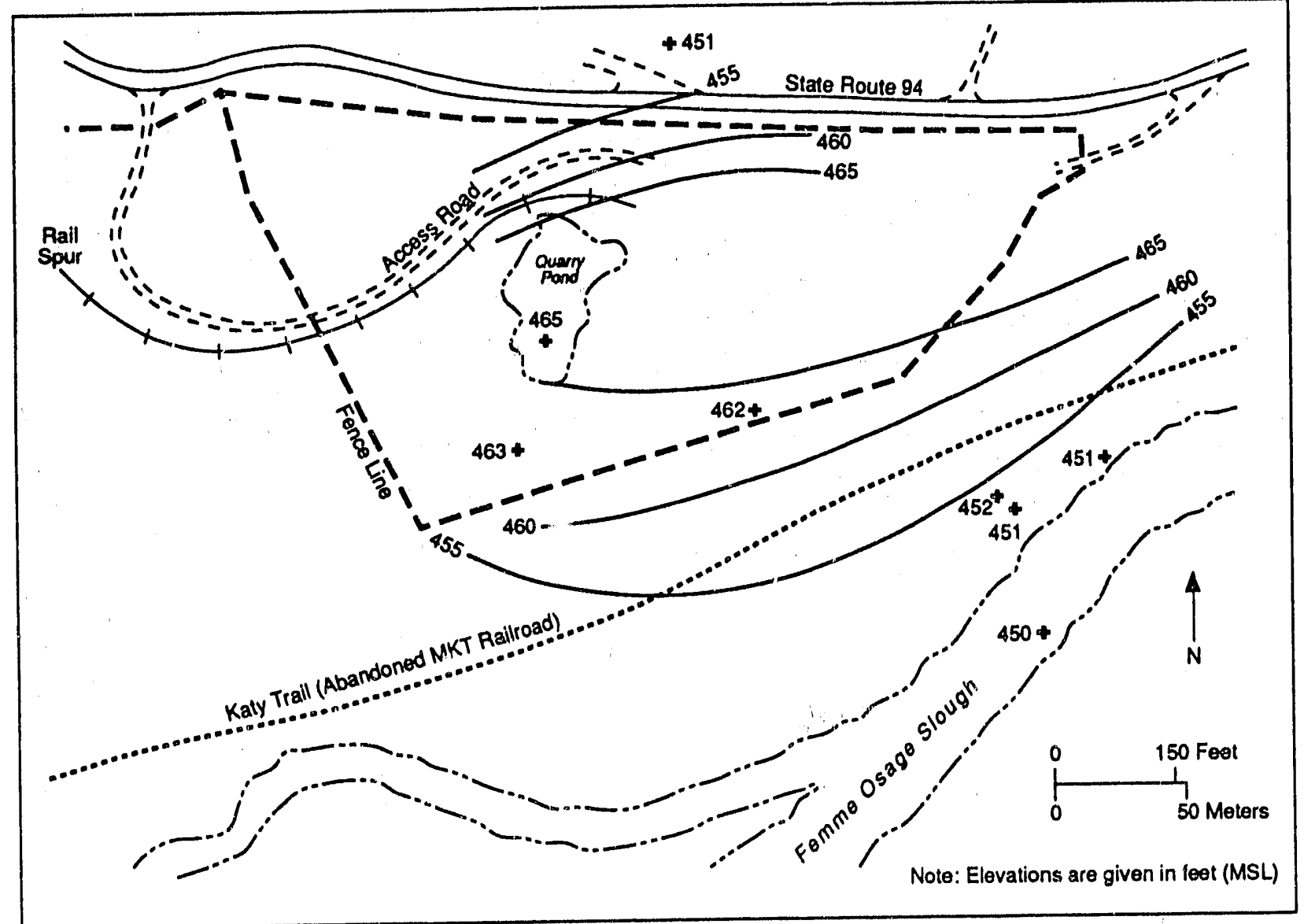

FIGURE 1.5 Water Levels Measured near the Weldon Spring Quarry in 1987 (Source: Argonne National Laboratory 1990)

Since 1960 , groundwater in the quarry bedrock has been sampled for radiological parameters (MK-Ferguson Company and Jacobs Engineering Group 1989). Total uranium concentration ranges from 3 to $18,700 \mathrm{pCi} / \mathrm{L}$, with the highest concentrations found in the southeast region of the quarry site (MW-1003 [Fig. 1.6] in 1977). Elevated uranium concentrations have been observed in four monitoring wells installed north of the Femme Osage Slough (MW-1013, MW-1014, MW-1015, and MW-1016) in 1987; however, no abovebackground radionuclide concentrations were found in monitoring wells ( $M W-1017$, $M W-1018$, and $M W-1019$ ) south of the slough (MK-Ferguson Company and Jacobs Engineering Group 1987). These results indicate that contaminated groundwater has migrated into the fine-grained alluvium north of the slough but not beyond it.

The first comprehensive chemical groundwater evaluation for the Weldon Spring quarry was performed in March 1987 (MK-Ferguson Company and Jacobs Engineering Group 1987). Ten monitoring wells in the quarry area were sampled and analyzed for radiological parameters, priority pollutants, pesticides, polychlorinated biphenyls (PCBs), nitroaromatics, metals, and inorganic anions (MK-Ferguson Company and Jacobs Engineering Group 1989). Nitrate levels in excess of drinking water standards were 


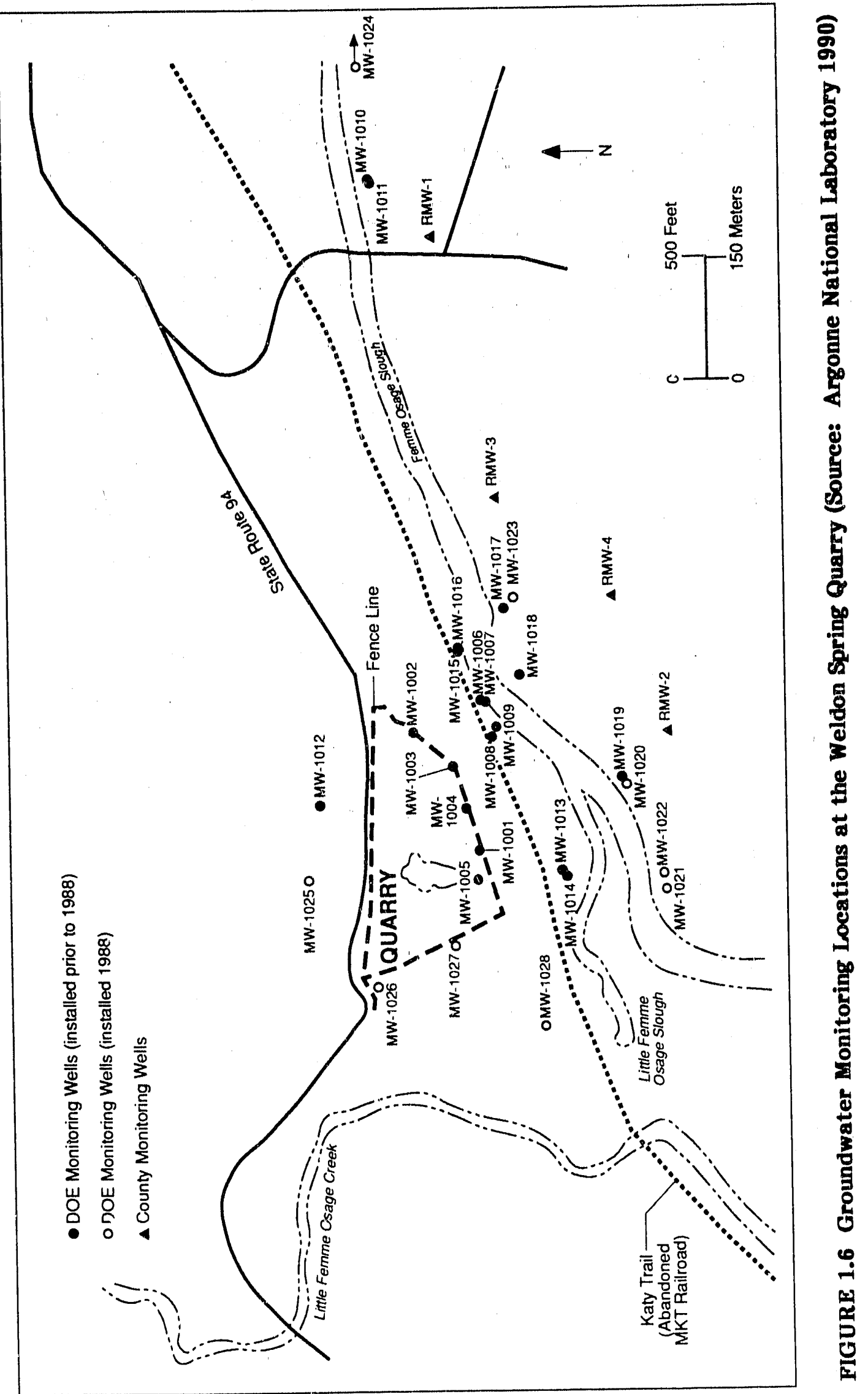


observed in monitoring wells $\mathrm{MW}-1004$ and $\mathrm{MW}-1005$; elevated sulfate concentrations were observed in numerous monitoring wells. In general, high-level concentrations of chemicalc wera found in the same wells that exhibited high radionuclide concentrations.

\subsection{PROBLEM}

Both hydrological and chemical information from the Weldon Spring quarry and vicinity properties indicate that the Femme Osage Slough is acting as an effective barrier to contaminant transport. In Sec. 2, a one-dimensional analytical solution is developed to investigate the effects of a zero-concentration boundary condition at the slough on upstream contaminant transport and the effects of dewatering the quarry pond. 


\section{TRANSPORT MODEL}

\subsection{THEORY: NATURAL FLOW}

Freeze and Cherry (1979) present the following partial differential equation $(\mathrm{PDE})$ to represent one-dimensional advection and dispersion of a solute in a porous medium:

$$
\frac{\partial C}{\partial t}+V \frac{\partial C}{\partial X}=D \frac{\partial^{2} C}{\partial x^{2}}
$$

Equation 2.1 can be cast into dimensionless form by making the following substitutions:

$$
\begin{aligned}
& X=X / X_{L} \\
& C=C / C_{0} \\
& t=\frac{t D}{X_{L}^{2}}
\end{aligned}
$$

and

$$
P e=\frac{V X_{L}}{D}=\text { Peclet number }=\begin{aligned}
& \text { ratio of advective to } \\
& \text { dispersive transport }
\end{aligned}
$$

where:

$$
\begin{aligned}
& \mathrm{X}_{\mathrm{L}}=\text { arbitrary scaling distance, } \\
& \mathrm{X}=\text { longitudinal spatial coordinate, } \\
& \mathrm{C}_{0}=\text { peak concentration at the source, } \\
& \mathrm{C}=\text { solute concentration, } \\
& \mathrm{V}=\text { specific discharge (Darcy velocity/effective porosity), } \\
& \mathrm{t}=\text { time, and } \\
& \mathrm{D}=\text { coefficient of dispersion. }
\end{aligned}
$$


The resultant dimensionless advection-dispersion equation is

$$
\frac{\partial C}{\partial t}+P e \frac{\partial C}{\partial X}=\frac{\partial^{2} C}{\partial X^{2}}
$$

Applying the Laplace transform method (Kreyszig 1967) to Eq. 2.6, under an assumed condition of zero initial solute concentration, yields the following result:

$$
s \bar{C}+P e \frac{d \bar{C}}{d X}=\frac{d^{2} \bar{c}}{d X^{2}}
$$

The general solution to the above ordinary differential equation (ODE) is given by the expression

$$
\bar{c}=C_{1} e^{\frac{P e X}{2}}-\sqrt{\frac{P e^{2} x^{2}+s x^{2}}{4}}+C_{2} \frac{P e X}{e^{2} e} \sqrt{\frac{P e^{2} x^{2}}{4}+s x^{2}}
$$

where $C_{1}$ and $C_{2}$ are arbitrary constants.

To eliminate the arbitrary constants in Eq. 2.8 in Laplace space, two spatial boundary conditions are required. First, the concentration of the contaminant is assumed to go to zero as $\mathrm{X}$ goes to infinity. That is,

$$
\operatorname{LIM}_{X+\infty} \bar{C}=0
$$

Equation 2.8 then reduces to

$$
\bar{c}=C_{1} e \frac{P e X}{2} e^{-\sqrt{\frac{P e^{2} x^{2}}{4}+s x^{2}}}
$$

A second spatial boundary condition is then applied at the location of the source $(X=0)$. The concentration is assumed to equal $\mathrm{C}_{0}$ at time zero and remain equal to $\mathrm{C}_{0}$ until time $\Delta t$, at which point the concentration returns to zero. For generality, a time-dependent step function is assumed. Hildebrand (1976) writes this function as

$$
\frac{C}{C_{0}}=U(t-0)-U(t-\Delta t)
$$

where $U$ is the unit function. 
In Laplace space, the above boundary condition transforms to

$$
\left.\bar{c}\right|_{X=0}=\frac{1}{s}\left(1-e^{-\Delta t s}\right)
$$

The value of the arbitrary constant $C_{1}$ in Eq. 2.10 can then be found by substituting Eq. 2.12 into Eq. 2.10. The result is

$$
c_{1}=\frac{1}{s}\left(1-e^{-\Delta t S}\right)
$$

The solution for the dimensionless solute concentration in Laplace space (Eq. 2.10) can then be rewritten as

$$
\bar{c}=\left(\frac{1-e^{-\Delta t S}}{S}\right) e^{\frac{P \in X}{2}} e^{-\sqrt{\frac{P e^{2} X^{2}}{4}+s x^{2}}}
$$

The terms of Eq. 2.14 can be inverted using the following relationship presented by Ditkin and Prudnikov (1967):

$$
\begin{aligned}
L^{-1}\left(\frac{\left.e^{-\sqrt{a(b+s)}}\right)=}{s}\right. & \frac{1}{2}\left[e^{-\sqrt{a b}} \operatorname{ERFC}\left(\frac{1}{2} \sqrt{\frac{a}{t}}-\sqrt{b t}\right)\right. \\
& \left.+e^{\sqrt{a b}} \operatorname{ERFC}\left(\frac{1}{2} \sqrt{\frac{a}{t}}+\sqrt{b t}\right)\right]
\end{aligned}
$$

where ERFC is the complementary error function given by Hildebrand (1976) as

$$
\operatorname{ERFC}(\gamma)=1-\operatorname{ERF}(\gamma)=1-\frac{2}{\sqrt{\pi}} \int_{0}^{\gamma} e^{-\lambda^{2}} d \lambda
$$

and the following shift identity for Laplace transforms (Hildebrand 1976):

$$
e^{-\Delta t S} f(S)=L(f(t-\Delta t) H(t-\Delta t))
$$


The solution to Eq. 2.14 in real time and space is then

$$
\begin{aligned}
C= & \frac{1}{2}\left[\operatorname{ERFC}\left(\frac{1}{2} \sqrt{\frac{X^{2}}{t}}-\sqrt{\frac{P e^{2} t}{4}}\right)+e^{P e X} \operatorname{ERFC}\left(\frac{1}{2} \sqrt{\frac{x^{2}}{t}}+\sqrt{\frac{P e^{2} t}{4}}\right)\right. \\
& -\frac{H(t-\Delta t)}{2}\left(\operatorname{ERFC}\left(\frac{1}{2} \sqrt{\frac{x^{2}}{t-\Delta t}}-\sqrt{\frac{P e^{2}(t-\Delta t)}{4}}\right)\right. \\
& \left.+e^{P \operatorname{PeX}} \operatorname{ERFC}\left(\frac{1}{2} \sqrt{\frac{x^{2}}{t-\Delta t}}+\sqrt{\frac{P e^{2}(t-\Delta t)}{4}}\right)\right)
\end{aligned}
$$

where $\mathrm{H}$ is the Heaviside function (Hildebrand 1976), such that

$$
\begin{aligned}
H(t-\Delta t) & =0 & & \text { for } t<\Delta t \\
& =1 & & \text { for } t \geq \Delta t
\end{aligned}
$$

Parameters of interest for the Weldon Spring quarry include the following:

$$
\begin{aligned}
\mathrm{X} & =\frac{\mathrm{X}}{\mathrm{L}} \\
t & =\frac{\mathrm{tD}}{\mathrm{L}^{2}} \\
\text { and } \mathrm{Pe} & =\frac{V L}{D}
\end{aligned}
$$

The coefficient of dispersion, $D$, is defined by Bear (1979) as

$$
D=a V+D *
$$

where $D^{*}$ is the coefficient of diffusion (assumed to be negligible in the following calculations due to the magnitude of advective flow and dispersion) and $\alpha$ is the dispersivity.

For small distances, dispersivity is scale dependent and given by the following approximation (Lallemand-Barres and Peaudecerf 1978):

$$
a=0.12
$$


where $L$ is the distance from the quarry pond to the slough (approximately $213 \mathrm{~m}$ $[700 \mathrm{ft}])$.

Using the Lallemald-Barres and Peaudecerf (1978) approximation, the Peclet number for the Weldon Spring Quarry is simply given by the following value:

$$
\mathrm{Pe}=\frac{V L}{0.1 \mathrm{LV}}=10
$$

The average linear velocity (Darcy velocity/effective poro ity) used in the above relations can range from about 30 to $305 \mathrm{~m} / \mathrm{d}(100$ to $1000 \mathrm{ft} / \mathrm{d})$ in the vicinity of the quarry, depending on the characteristics of the porous medium (alluvium or limestone). A base-case value of $91 \mathrm{~m} / \mathrm{c}(300 \mathrm{ft} / \mathrm{d})$ was assumed to be representative for all subsequent calculations. This base-case value is consistent with point-dilution measurements made in the fractured limestone near the quarry (Berkeley Geosciences Associates 1984) and is a reasonable compromise between the high fluid velocities expected in the fractured limestone and the low fluid velocities expected in the floodplain alluvium north of the slough (Tumasko 1989).

Figures 2.1 and 2.2 show the results of calculations performed for step functions of 20 - and $30-y r$ durations. The simplifying assumptions and site-specific hydrological parameters discussed previously were used in the calculations. The longer the duration of the source at $X=0$, the higher the spatial concentration of the solute. For very long times, $t$, the pulse of contaminant moves longitudinally along the $X$-axis toward $X=$ infinity as demonstrated in Fig. 2.3. The broadening observed in the initial square-wave source term is caused by longitudinal dispersion in the advective direction. The peak amplitude of the contaminant "slug," however, is time invariant due to the assumed conservative nature of the solute (i.e., no nonreversible sorption processes).

The zero-concentration model is constrained to allow the solute concentration to go to zero as the spatial separation goes to infinity. For the case of interest, the Femme Osage Slough located at $X=1$, it is assumed that the dimensionless solute concentration is held at zero. That is,

$$
\operatorname{LIM}_{x+1} C=0
$$

For the Femme Osage Slough, the solution to Eq. 2.7 in Laplace space is again given by the general solution presented in Eq. 2.8. The two arbitrary constants that appear in Eq. 2.8 can be eliminated by using spatial boundary conditions at $X=0$ and $X=1$.

For a step-function source at $X=0$, the appropriate boundary conditions are given by

$$
\left.\bar{c}\right|_{X=0}=\frac{1}{s}\left(1-e^{-\Delta t s}\right)
$$

and at $X=1$, the Laplace-space concentration is identically equal to zero. 


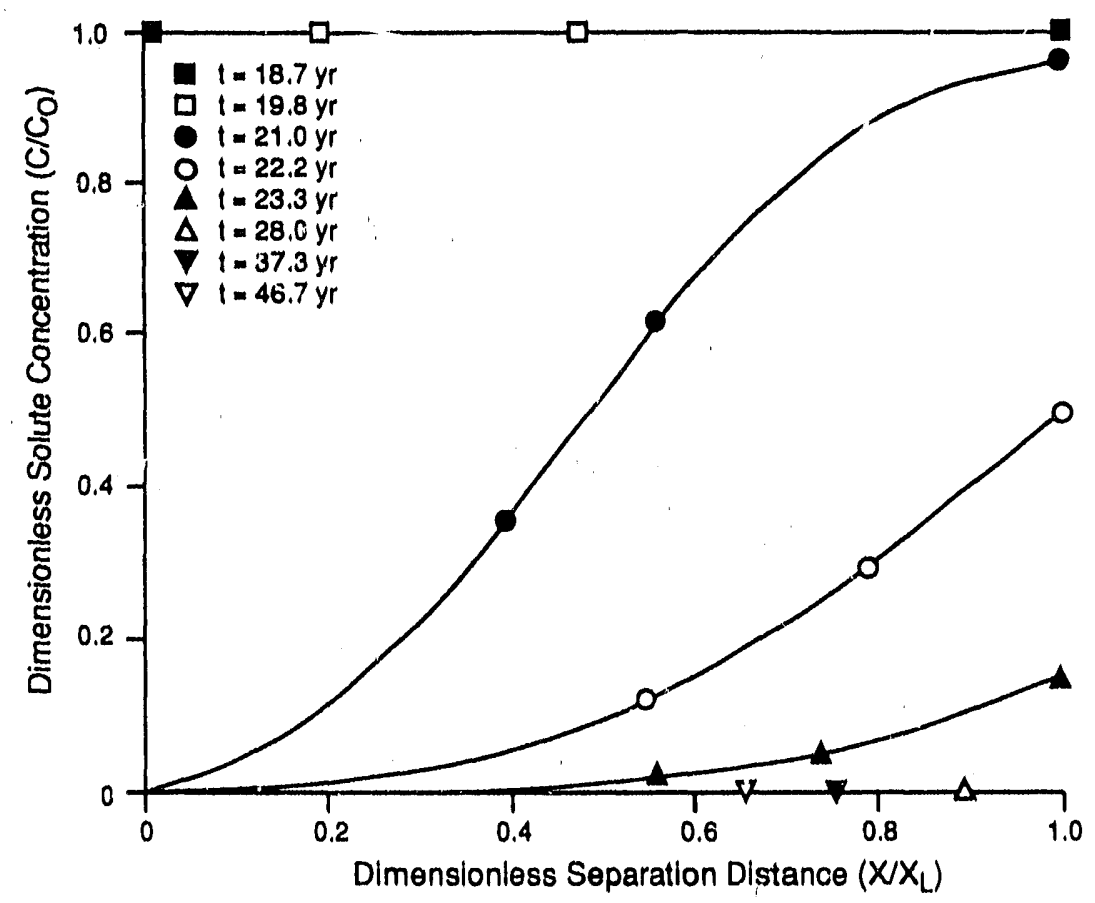

FIGURE 2.1 Concentration versus Distance for a Zero-Concentration Boundary at $\mathrm{X}=$ Infinity;

$\mathrm{Pe}=10, \Delta \mathrm{t}=20 \mathrm{gr}$

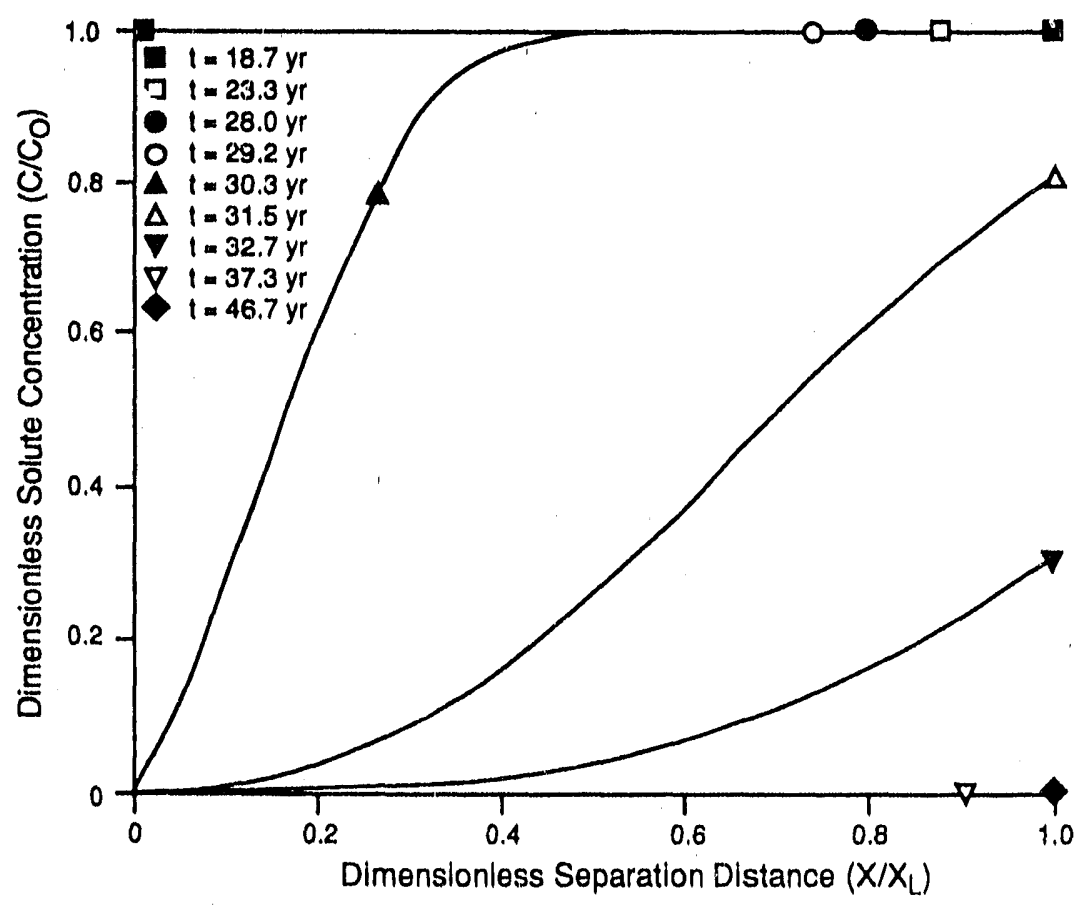

FIGURE 2.2 Concentration versus Distance for a Zero-Concentration Boundary at $X=$ Infinity;

$\mathrm{Pe}=10, \Delta \mathrm{t}=30 \mathrm{yr}$ 


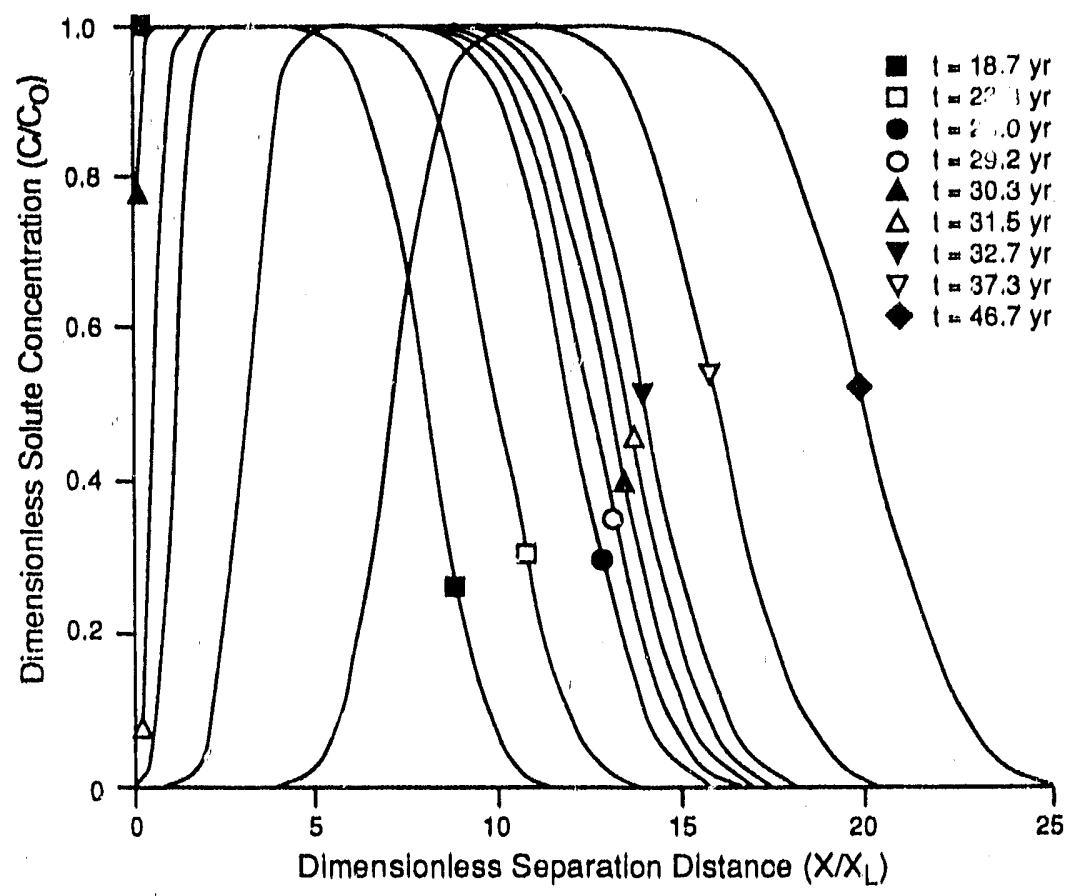

FIGURE 2.3 Longitudinal Contaminan $\downarrow$ Migration as a Function of Space and Time for a Zero-Concentration Boundary at $X=$ Infinity; $P e=10, \Delta t=30 \mathrm{yr}$

Use of the above two relations in Eq. 2.8 ylelds the following result:

$$
\begin{aligned}
\bar{c}= & \frac{e^{\frac{P e X}{2}}}{s}\left(\frac{1-e^{-\Delta t s}}{1-e^{\sqrt{P e^{2}+4 s}}}\right) \\
& \left(e^{\sqrt{\frac{P e^{2} X^{2}}{4}+s x^{2}}-e^{\sqrt{P e^{2}+4 s}}} e^{-\sqrt{\frac{P e^{2} x^{2}+s x^{2}}{4}}}\right)
\end{aligned}
$$

A search of standard Laplace transform tables did not produce any simple analytic inversion of the required solution. Applying the Stehfest algorithm (Stehfest 1970a, 1970 b) did not produce useful results because the algorithm cannot replicate abrupt amplitude transitions, such as those in the assumed square-wave source term (Davies and Martin 1979). This behavior is demonstrated in Fig. 2.4 for a step function of 10-yr duration calculated with the Stehfest algorlihm. Significant, artificial dispersion is introduced, thereby negating the method's applicability. 


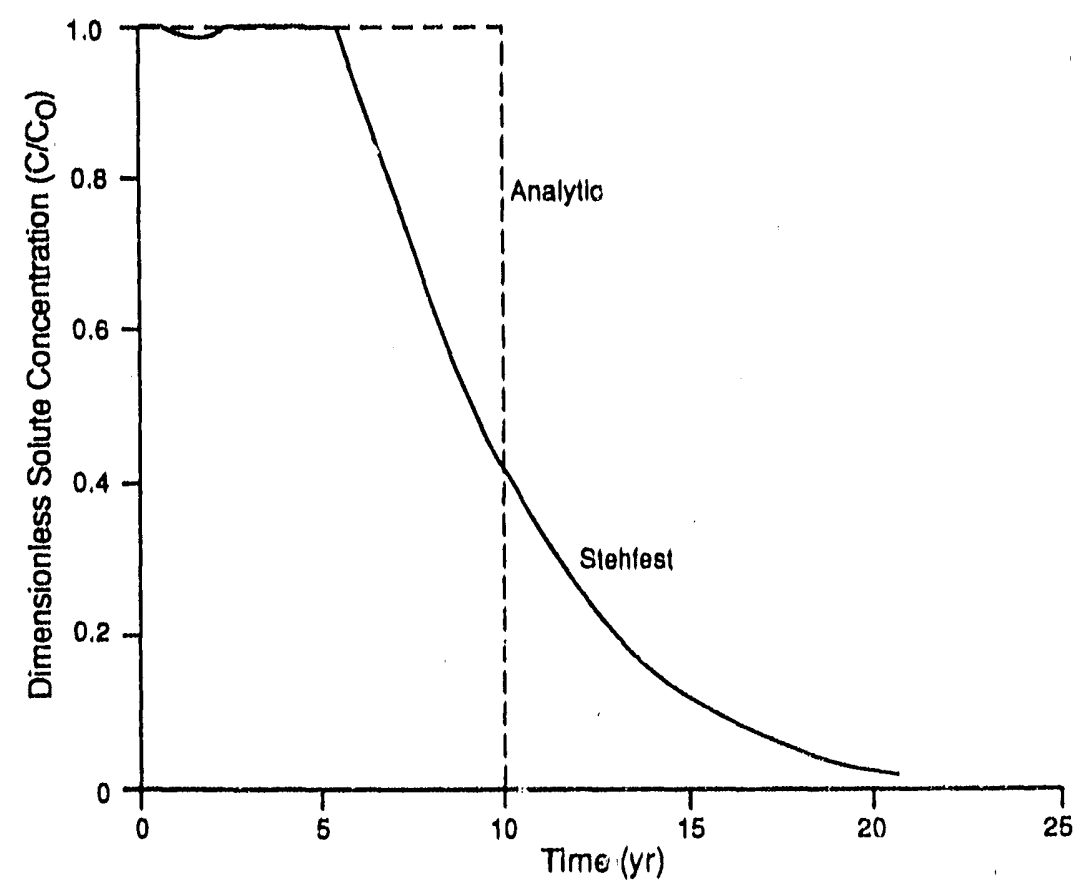

FIGURE 2.4 Reproduction of a Square-Wave Source Using the Stehfest Algorithm

In 1968, Dubner and Abate introduced the concept of numerically inverting Laplace transforms using the real portion of a Fourier series. This method is particularly well suited for functions with abrupt amplitude transitions. Crump (1976) improved on the method by making use of both the real and Imaginary terms of a Fourier series. In this approach,

$$
\begin{aligned}
f(t) & =\frac{e^{c t}}{2 T_{m}}\left(\frac { 1 } { 2 } \left(F(c)+\sum_{K=1}^{\infty}\left[\operatorname{Re} F\left(c+\frac{K \pi i}{2 T_{m}}\right) \cos \left(\frac{K \pi t}{2 T_{m}}\right)\right.\right.\right. \\
& \left.\left.-\operatorname{Im} F\left(c+\frac{K \pi i}{2 T_{m}}\right) \operatorname{SIN}\left(\frac{K \pi t}{2 T_{m}}\right)\right]\right)
\end{aligned}
$$

where:

$$
\begin{aligned}
\text { Re } & =\text { real part of the complex function, } \\
I m & =\text { imaginary part of the complex function, } \\
c & =5 / T_{m} \text {, and } \\
T_{m} & =\text { maximum time of the calculation. }
\end{aligned}
$$


In implementing Eq. 2.29, the Laplace variable $\mathrm{S}$ is replaced with its complex counterpart:

$$
s=c+d i
$$

where:

$$
\begin{aligned}
& \mathrm{c}=5 / T_{m}, \\
& d=\frac{K \pi}{2 T_{m}}, \text { and } \\
& i=\sqrt{-1} .
\end{aligned}
$$

To implement Eq. 2.29, $F(c)$ and $F(S)$ must be formed from Eq. 2.29. The results are

$$
\begin{aligned}
F(c)= & \frac{e^{\frac{P e X}{2}}}{c}\left(\frac { 1 - e ^ { - \Delta t c } } { 1 - e \sqrt { P ^ { 2 } + 4 c } } \left(e^{\sqrt{\frac{P e^{2} x^{2}}{4}+c X^{2}}}\right.\right. \\
& -e^{\left.\left.\sqrt{P e^{2}+4 c} e^{-\sqrt{\frac{P e^{2} X^{2}}{4}+c s^{2}}}\right)\right)}
\end{aligned}
$$

and

$$
\begin{aligned}
& F(s)=F(c+d i)=\frac{(c-d i)}{c^{2}+d^{2}} e^{\frac{P e X}{2}} \\
& \left(\frac{1-e^{-\Delta t(c+d i)}}{i-e \sqrt{P e^{2}+4(c+d i)}}\right)\left(e^{\sqrt{\frac{P e^{2} x^{2}}{4}+(c+d i) x^{2}}}\right.
\end{aligned}
$$

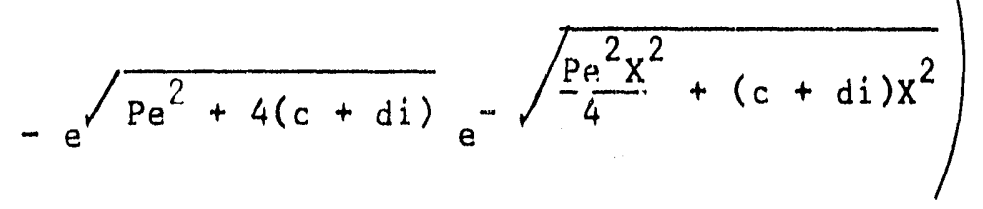

where the denominator of Eq. 2.32 has been rationalized. 
Subtituting Egs. 2.j: and 2.32 in Eq. 2.29 gives the following complex expression for the concentration in real time and space:

$$
\begin{aligned}
& c(t)=f(t) \simeq \\
& \frac{e^{c t}}{2 T}\left(\frac { 1 } { m } \left(\frac{e^{\frac{P e X}{2}}}{c}\left(\frac{1-e^{-\Delta t c}}{1-\sqrt{P e^{2}+4 c}}\right)\left(e^{\sqrt{\frac{P e^{2} x^{2}}{4}+c x^{2}}}-e^{\sqrt{P e^{2}+4 c}} e^{-\sqrt{\frac{P e^{2} x^{2}}{4}+c x^{2}}}\right)\right.\right. \\
& +\sum_{k=1}^{\infty}\left[\operatorname { R e } \left(\frac{(c-d i)}{c^{2}+d^{2}}\left(\frac{1-e^{-\Delta t(c+d i)}}{1-e^{P e^{2}+4(c+d i)}}\right) e^{\frac{P e X}{2}}\right.\right. \\
& \left(\sqrt{\frac{P e^{2} x^{2}}{4}+(c+d i) x^{2}}-\sqrt{P e^{2}+4(c+d i)} e^{-\sqrt{\frac{P e^{2} x^{2}}{4}+(c+d i) x^{2}}}\right) \\
& \left.\cos \left(\frac{K \pi t}{T_{m}}\right)\right)-I M\left(\frac{(c-d i)}{c^{2}+d^{2}}\left(\frac{1-e^{-\Delta t(c+d i)}}{1-\sqrt{P e^{2}+4(c+d i) X^{2}}}\right) e^{\frac{P e X}{2}}\right. \\
& \left(\sqrt{\frac{P e^{2} x^{2}}{4}+(c+d i) x^{2}}-\sqrt{P e^{2}+4(c+d i)}-\sqrt{\frac{P e^{2} x^{2}}{4}+(c+d i) x^{2}}\right) \\
& \left.\left.\sin \left(\frac{K \pi t}{2 T_{m}}\right)\right] \int\right)
\end{aligned}
$$


For computation, terms of the form,

$$
e^{\sqrt{r_{1}+r_{2} i}}
$$

are inconventent. Such terms can be managed, however, by making use of the following transformation from Wunsch (1983):

$$
e^{\sqrt{X+i Y}}=e^{a+i b}
$$

for

$$
a= \pm \frac{\sqrt{x+\sqrt{x^{2}+y^{2}}}}{\sqrt{2}}
$$

and

$$
b= \pm \frac{\sqrt{-x+\sqrt{x^{2}+x^{2}}}}{\sqrt{2}}
$$

(Note: \pm signs on the radicals must be paired [i.e., both must be plus, or both musi be negative]. Identical results are obtained for elther both plus or both minus.)

The relationship

$$
e^{a+i b}
$$

can be more conveniently managed by using the following property of the complex exponential function (Wunsch 1983):

$$
e^{a+i b}=e^{a}(\cos b+i \sin b)
$$

A computer program was written to solve Eq. 2.33. Absolute convergence of the solute concentration to within 0.001 was typically achieved by using a $\mathrm{K}$ value of 3000 . With this many terms in the Fourier series, computation time is lengthy. To eliminate this difficulty, convergence of the solution was accelerated (Macdonald 1964) by employing the epsilon algorithm of Wynn (1956). To decrease computer storage, the algorithm that was developed used a three-column approach with continuous updating. Use of the epsilon algorithm reduced the number of terms in the series to fewer than 100 without significantly affecting numerical accuracy. In addition, to ensure functional smoothness, additional terms in the Fourier series were retained if the inverted function was rapidly varying.

Figure 2.5 shows the dimensionless concentration as a function of time for various $X$ locations for a $\mathrm{Pe}$ of 10 and a step-function duration of $20 \mathrm{yr}$. For $\mathrm{X}=0$, excellent reproduction of the step-function is seen. At larger separations from the 


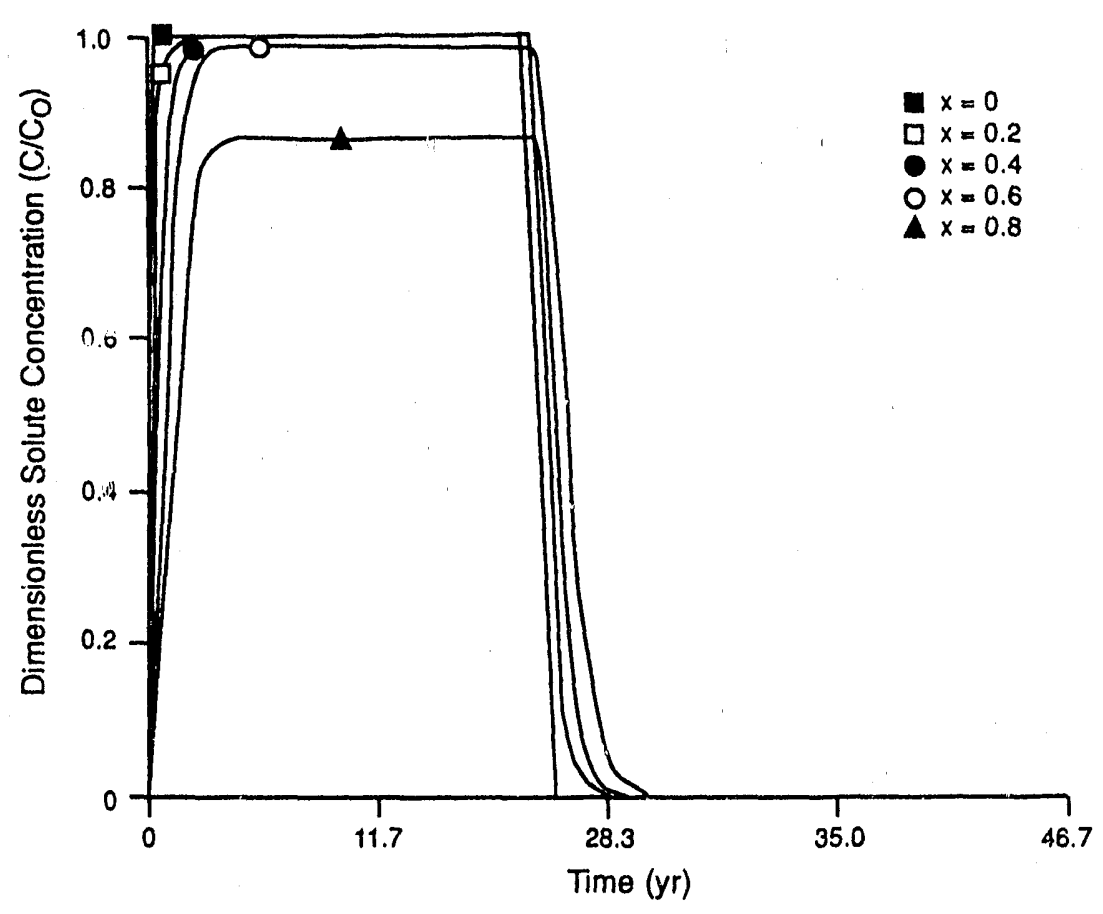

FIGURE 2.5 Concentration versus Time for a ZeroConcentration Sink at $X=1$ and $P e=10$, Using a Fourier Series Approach

source, a lag time is necessary before contaminant concentration rises above the initial value.

The results of decreasing the Pe from 10 to 5 are shown in Fig. 2.6. At lower $P e$ values, the lag times are increased; the peak ampliture reached is substantially less than that achieved for higher advective transport (i.e., a higher Pe). Again, reproduction of the step-function source at $X=0$ is excellent.

Figures 2.7, 2.8, and 2.9 show the buildup of dimensionless solute concentration as a function of spatial coordinate and time for Peclet numbers of 5, 10, and 20, respectively, and a step-function duration of $20 \mathrm{yr}$. At early time, longitudinal dispersion broadens the contaminant slug profile and the concentration quickly moves into a steadystate condition in which the concentration profile no longer changes with time. As expected, the quickest concentration buildup occurs for the highest $\mathrm{Pe}$.

For steady-state conditions to exist,

$$
\frac{\partial C}{\partial t}=0
$$

and

$$
\operatorname{Pe} \frac{d C}{d X}=\frac{d^{2} C}{d X^{2}}
$$




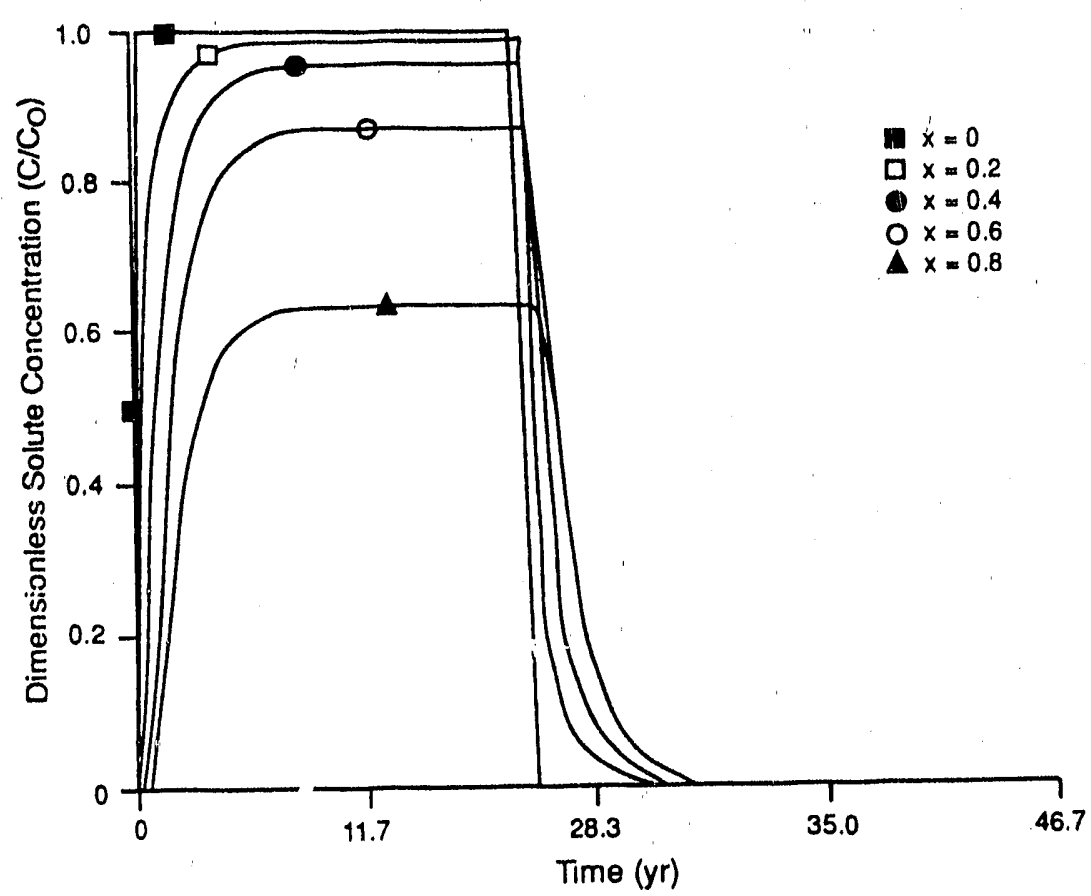

FIGURE 2.6 Concentration versus Time for a ZeroConcentration Sink at $\mathrm{X}=1$ and $\mathrm{Pe}=5$, Using a Fourier Series Approach

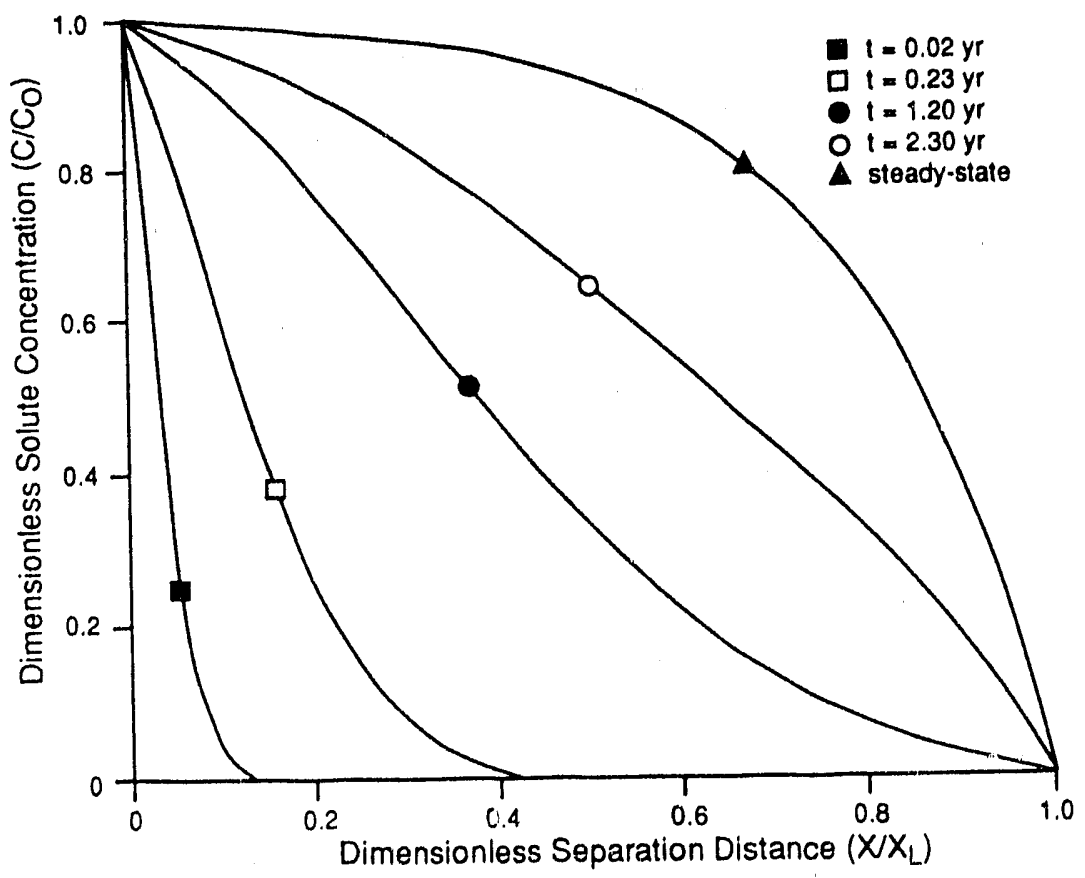

FIGURE 2.7 Concentration Buildup for $\mathrm{Pe}=5$ 


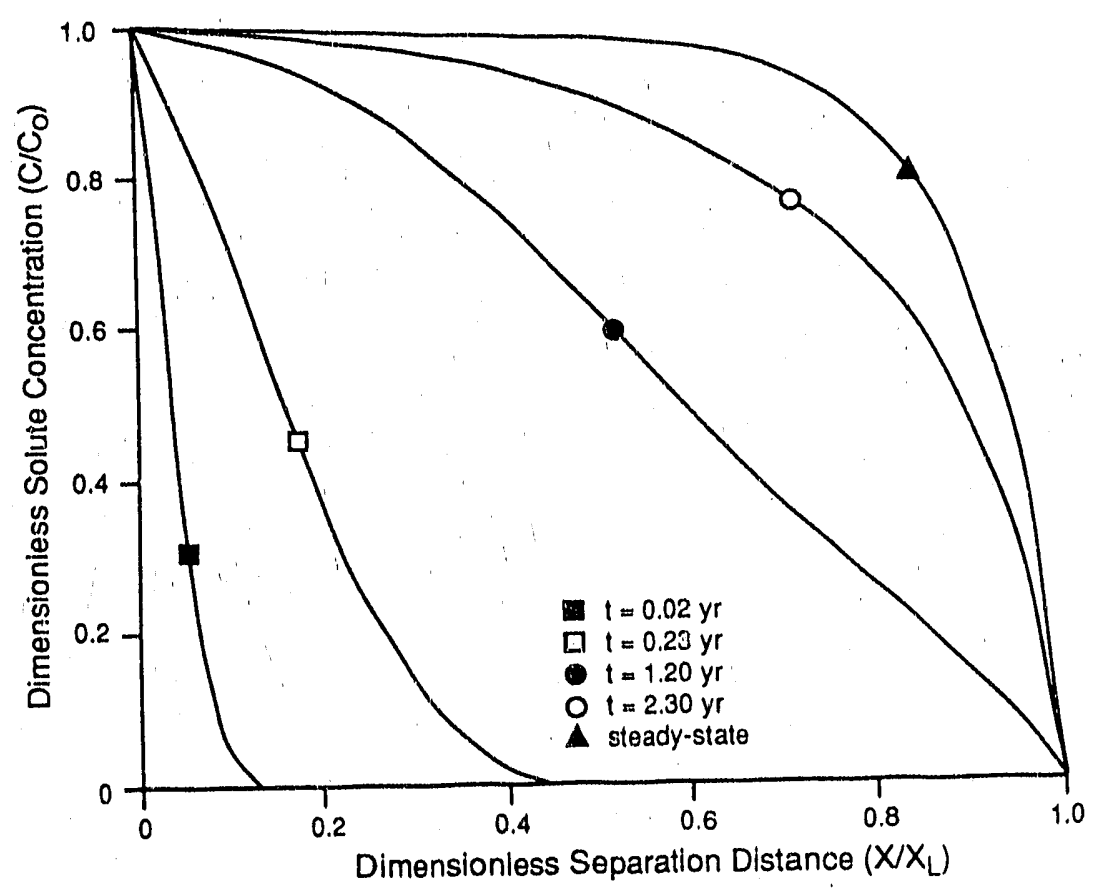

FU'GURE 2.8 Concentration Buildup for $\mathrm{Pe}=10$

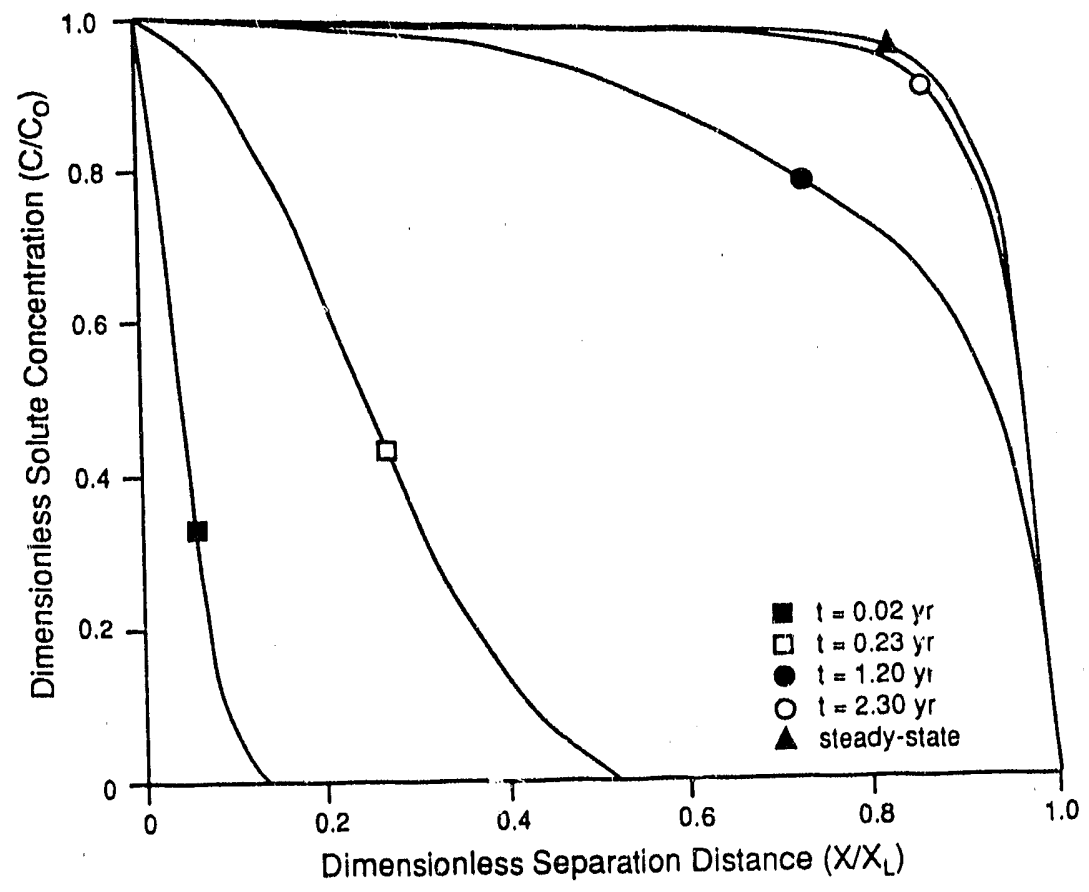

FIGURE 2.9 Concentration Buildup for $\mathrm{Pe}=\mathbf{2 0}$ 
For a constant strength source at $X=0$, the solution to Eq. 2.41 is given by

$$
\frac{c}{c_{0}}=\frac{1-e^{\operatorname{Pe}(x-1)}}{1-e^{-P e}}
$$

Plots of the behavior of $\mathrm{C} / \mathrm{C}_{0}$ versus $\mathrm{X}$ for various Peclet numbers are shown in Fig. 2.10. As expected, higher Pe flows produce higher spatial solute concentrations. When Pe equals 50, the steady-state concentration is nearly equal to 1.0 for all $\mathrm{X}$.

Once the step-function source is exhausted, the spatial distribution of concentration decays as shown in Figs. 2.11, 2.12, and 2.13, where the Peclet numbers are 5,10 , and 20 , respectively. The higher the Pe, the quicker the flow system returns to initial conditions.

Differences between spatial concentrations calculated with a model that assumes a zero-concentration sink at infinity, and one in which the zero-concentration sink is assumed to be at the slough $(702 \mathrm{~m}[2500 \mathrm{ft}])$ or the Missouri River $(1524 \mathrm{~m}[5000 \mathrm{ft}])$ are shown in Figs. 2.14 through 2.17 for $1,5,10$, and $20 \mathrm{yr}$, respectively. In all cases, the duration of the step function was assumed to be $20 \mathrm{yr}$ and the Pe equal to 20 . At early times (Fig. 2.14), the spatial concentrations of the contaminant are very similar. As time progresses, the concentrations predicted with the second model go to a steady-state profile, while the first model continues to predict transient concentrations with an ever changing profile. After $20 \mathrm{yr}$, the model-predicted concentrations are again very similar

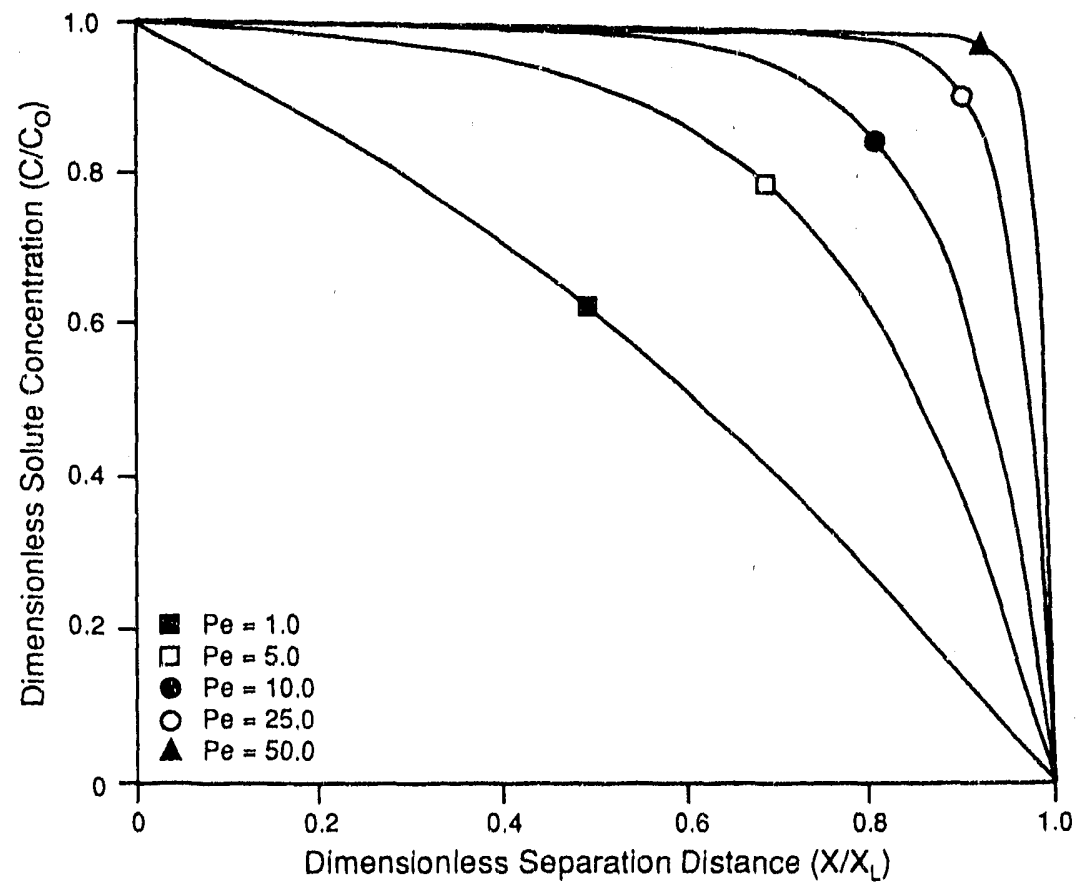

FIGURE 2.10 Steady-State Solutions for a ZeroConcentration Sink at $X=1$ as a Function of Space and $\mathrm{Pe}$ 


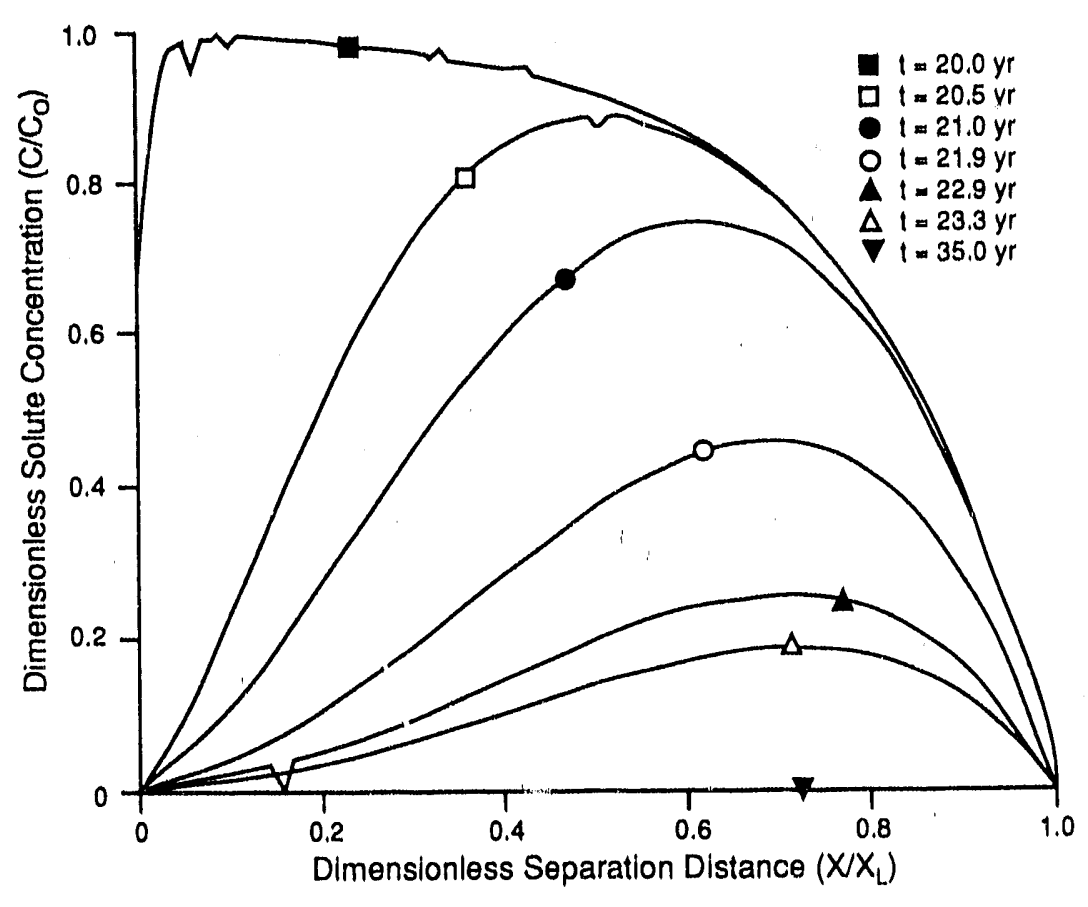

FIGURE 2.11 Concentration Decay for $\mathrm{Pe}=5$

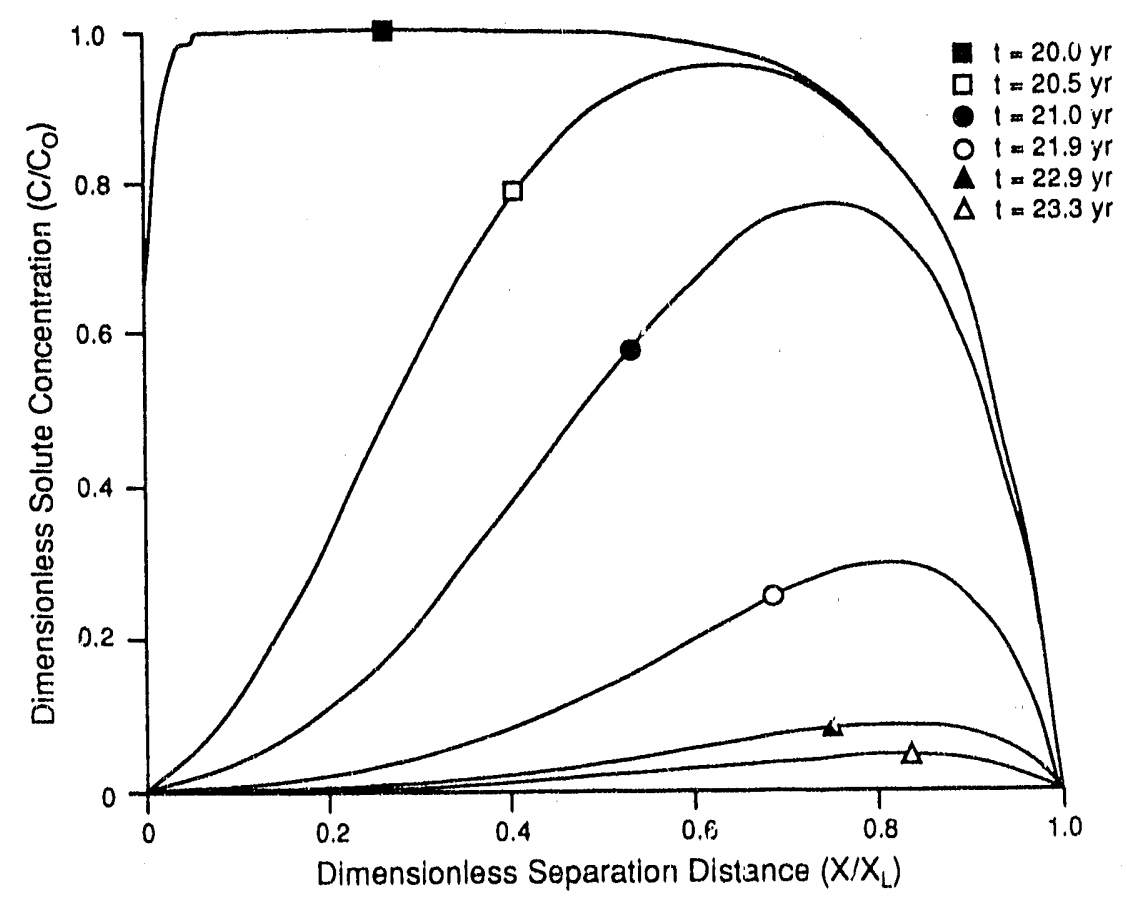

FIGURE 2.12 Concentration Decay for $\mathrm{Pe}=10$ 


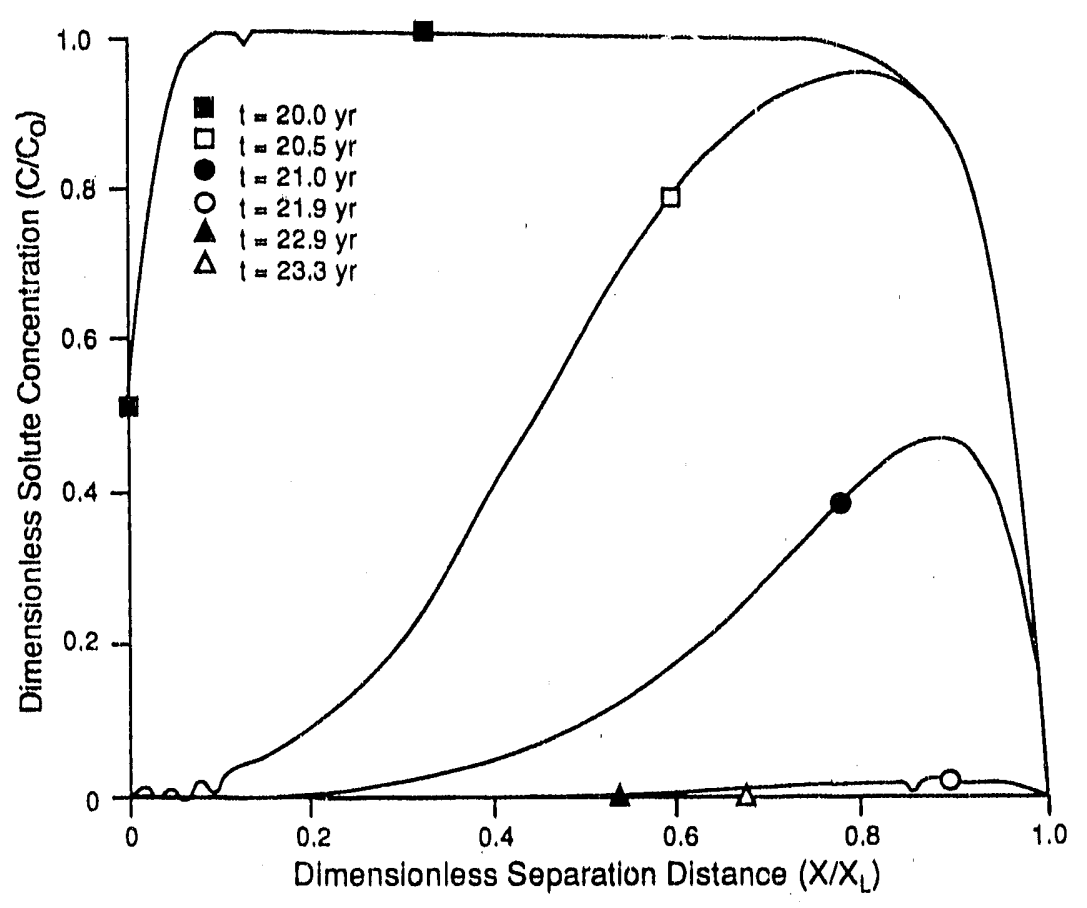

FIGURE 2.13 Concentration Decay for $\mathrm{Pe}=\mathbf{2 0}$

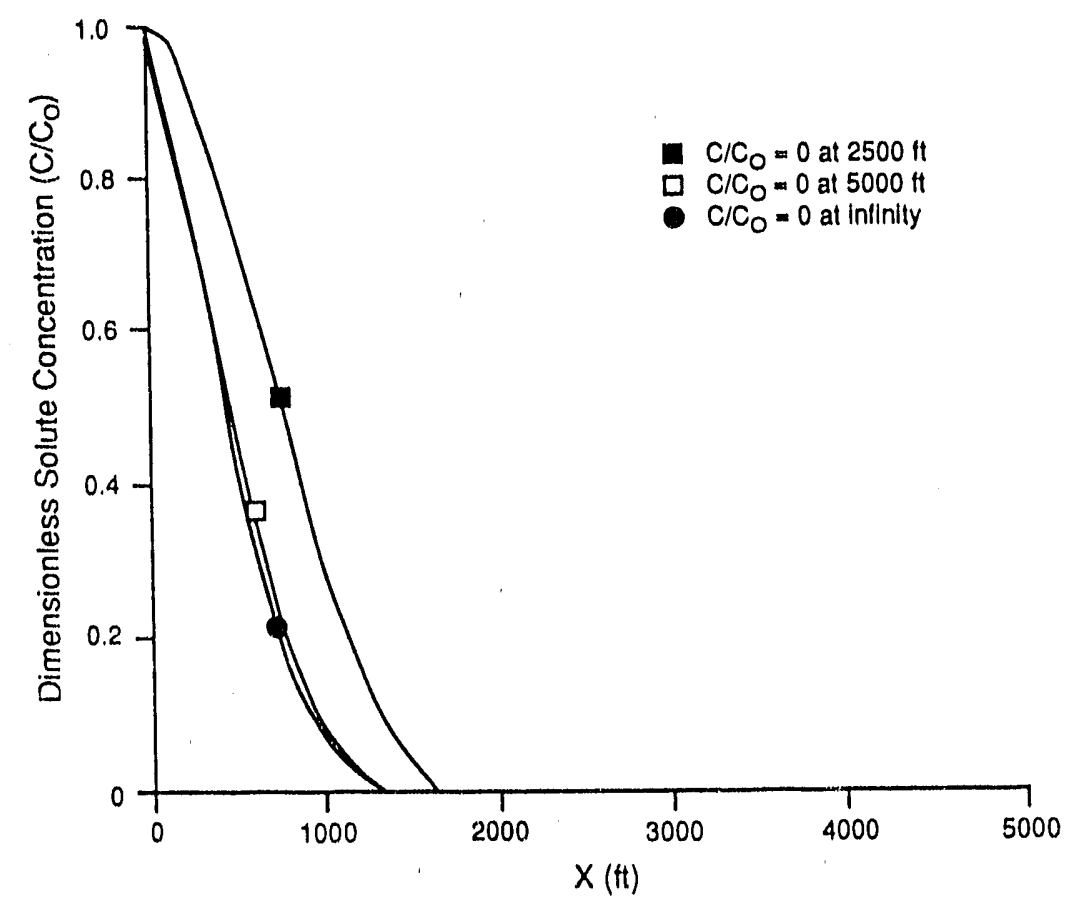

FIGURE 2.14 Comparison of Concentration versus Distance for Zero Boundary Conditions at $X=2500 \mathrm{ft}$, $5000 \mathrm{ft}$, and Infinity at $1 \mathrm{yr} ; \mathrm{Pe}=20, \Delta \mathrm{t}=20 \mathrm{yr}$ 


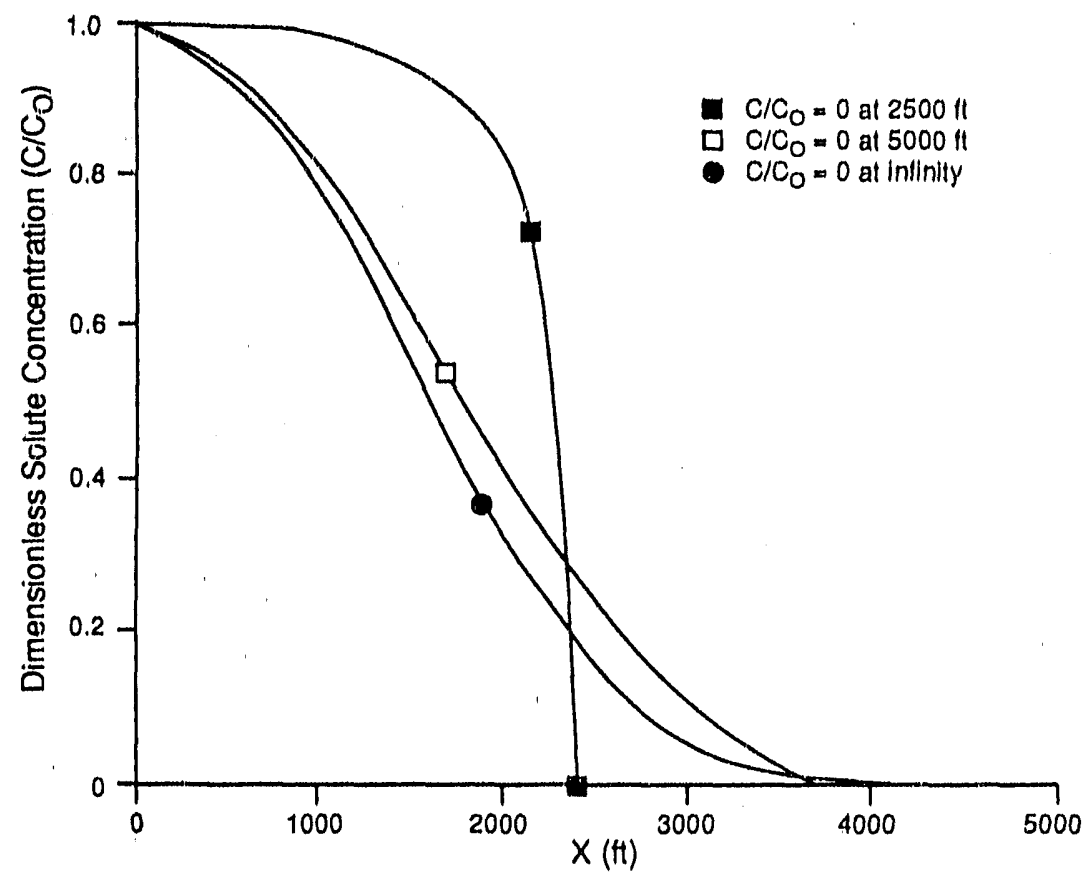

FIGURE 2.15 Comparison of Concentration versus Distance for Zero Boundary Conditions at $X=2500 \mathrm{ft}$, $5000 \mathrm{ft}$, and Infinity at $5 \mathrm{yr} ; \mathrm{Pe}=20, \Delta t=20 \mathrm{gr}$

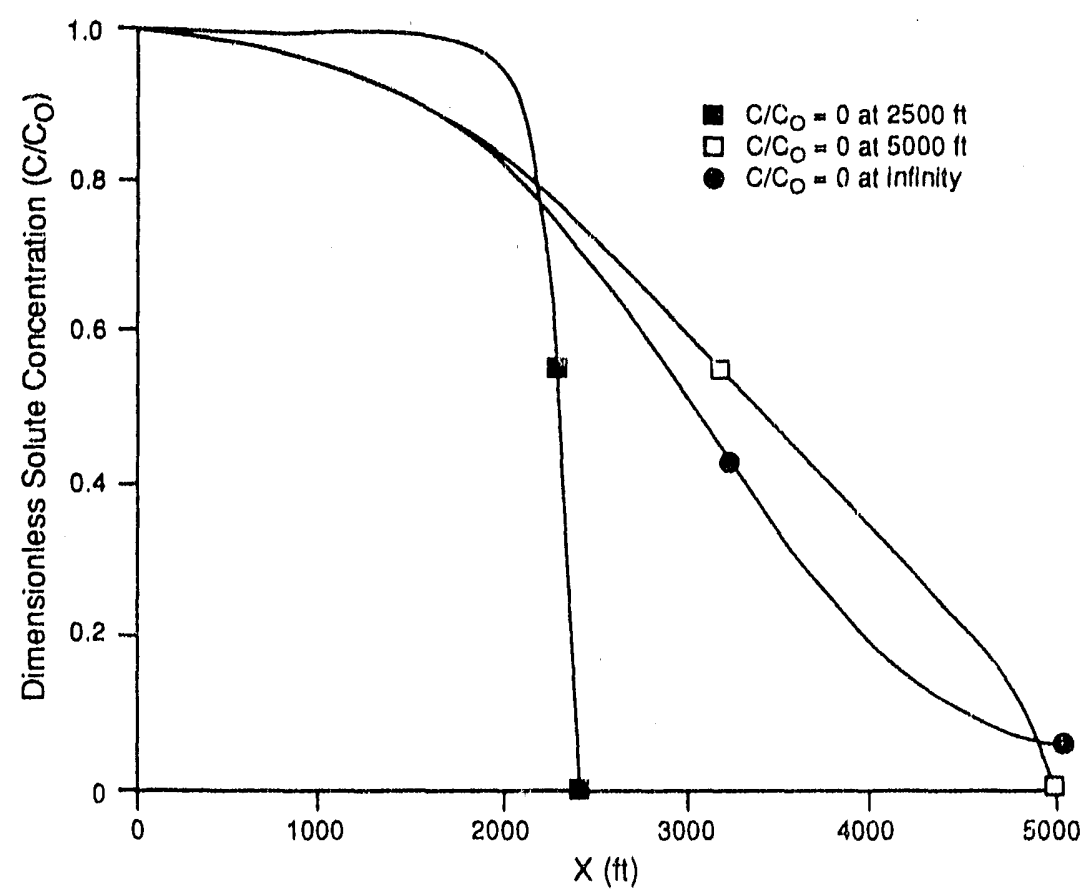

FIGURE 2.16 Comparison of Concentration versus Distance for Zero Boundary Conditions at $X=2500 \mathrm{ft}$, $5000 \mathrm{ft}$, and Infinity at $10 \mathrm{yr} ; \mathrm{Pe}=20, \Delta \mathrm{t}=20 \mathrm{yr}$ 


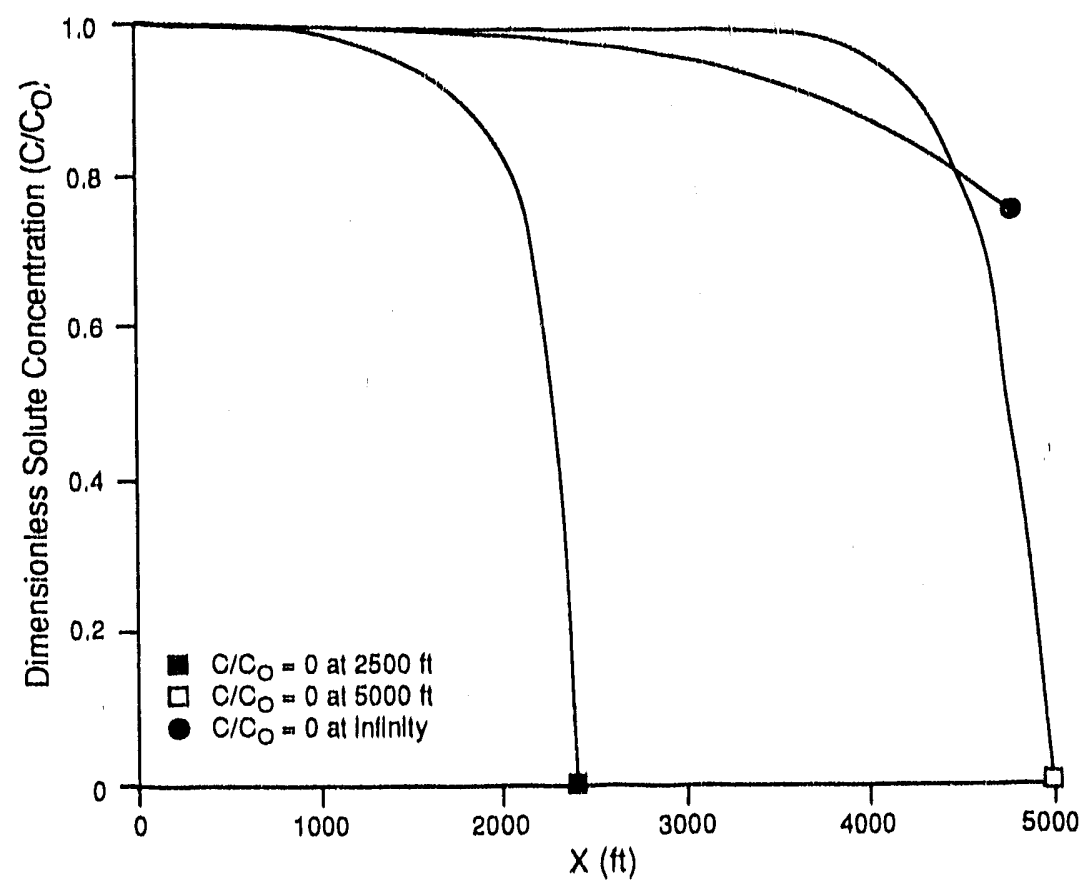

FIGURE 2.17 Comparison of Concentrition versus Distance for Zero Boundary Conditions at $X=2500 \mathrm{ft}$, $5000 \mathrm{ft}$, and Inf'nity at $20 \mathrm{gr} ; \mathrm{Pe}=20, \Delta \mathrm{t}=20 \mathrm{yr}$

(Fig. 2.17); however, the concentrations predicted with the finite-sink locations go to zero at prescribed separations. Differences between the models are also a function of the $\mathrm{Pe}$; the lower the $\mathrm{Pe}$, the greater the difference in spatial distributions for late-time behavior.

\subsection{THEORY: PUMP AT THE QUARRY}

As part of the response action planned at the Weldon Spring quarry, the DOE plans to dewater the quarry pond and remove the wastes. During the waste-removal process, pumps installed in the vicinity of the quarry will maintain a negative gradient so that groundwater will flow toward the quarry. This induced flow will inhibit any further migration of contaminants from the quarry toward the St. Charles municipal well field.

In sec. 2.1, it was shown that a zero-concentration sink at the Femme Osage Slough produces nearly steady-state spatial distributions in a relatively short time for site-specific hydrological parameters. For step functions of 20- to 30-yr durations, such as those likely to have been produced by disposal activities at the quarry in the late 1950 s and early $1960 \mathrm{~s}$, current solute concentrations should be nearly time invariant.

Remedial pump-back activities at the quarry will, thus, induce contaminant migration toward the quarry from an initial steady-state spatial distribution. In the remainder of this section, a one-dimensional pump-back theory will be developed and the effects of this activity evaluated. 
For simpliclty, purnp-back activitles are assumed to produce an Instantaneous gradient from the Femme Osage Slough to the quarry pond. It is also assumed that this gradient will produce a constant specific discharge equal to the Darcy velocity divided by the effective porosity.

In a natural coordinate system for the above pump-back geometry, the slough is located at a dimensionless distance, $X=0$; the quarry is located at $X=1$. To avold confusion with Sec. 2.1, calculational results for the pump-back geometry are shown plotted with the same orientation as that used for natural flow conditions, that is, $X=0=$ pond, and $X=1=$ slough. The initial contaminant concentration is assumed to be equal to the steady-state value achleved under no-puinping conditions. That is,

$$
c(t=0)=\frac{1-e^{-P e X}}{1-e^{-P e}}
$$

The governing PDE for contaminant migration for the pump-back geometry is the same as that given in Eq. 2.1; however, appllcation of the Laplace transform technique gives the following ODE for the concentration in Laplace space:

$$
s \bar{c}-\bar{C}(t=0)+P e \frac{d \bar{C}}{d X}=\frac{d^{2} \bar{c}}{d X^{2}}
$$

Equation 2.44 is identical to Eq. 2.7, except for the inclusion of the initial concentration term (Eq. 2.43).

ODE:

Grouping terms in Eq. 2.44 gives the following nonhomogeneous second-order

$$
\frac{d^{2} \bar{C}}{d X^{2}}-P e \frac{d \bar{C}}{d X}-s \bar{C}=-a+a e^{-P e X}
$$

where:

$$
a=\frac{1}{1-e^{-P e}}
$$

The general solution to Eq. 2.45 is given as the sum of a particular solution (Kreyszlg 1967), $\mathrm{C}_{\mathrm{p}}$, and the homogeneous solution, $\mathrm{C}_{\mathrm{h}}$.

$$
\bar{c}=C_{p}+C_{h}
$$

Using the variations-of-parameters technique (Kreyszig 1967), the particular solution, $\mathrm{C}_{\mathrm{p}}$, is given by the expression 


$$
C_{p}=\frac{a}{s}+\frac{a}{2 P e^{2}-g} e^{-P e X}
$$

The homogeneous solution, $\mathrm{C}_{h}$, is given by

$$
C_{h}=C_{1} e^{\frac{P e x}{2}} e^{\frac{P e^{2} x^{2}}{4}+s x^{2}}+C_{2} e^{\frac{P e X}{2}}-\sqrt{\frac{P e^{2} x^{2}}{4}+s x^{2}}
$$

Adding Eqs. 2.48 and 2.49 gives the following general expression for the contaminant concentration in Laplace space:

$$
\begin{aligned}
\vec{C}= & C_{1} e^{\frac{E \cdot X}{2}} e^{\frac{P e^{2} X^{2}}{4}+S x^{2}}+C_{2} e^{\frac{P e X}{2}} e^{-\sqrt{\frac{P e^{2} X^{2}}{4}+s x^{2}}} \\
& +\frac{a}{s}+\frac{a}{2 P e^{2}-s} e^{-P e X}
\end{aligned}
$$

To solve Eg. 2.50, two boundary condltions are required to ellminate the two arbitrary constants. The first boundary condition occurs at the location of the slough, $X=0$. At this location, the concentration is again assumed to equal zero. At the quarry, use of the pumps will produce a symmetric dropoff in concentration, like that expected for a zeroflux condition, that is,

$$
\left.\frac{\partial \bar{C}}{\partial X}\right|_{X=1}=0
$$

Manipulation of Eq. 2.50 with the two boundary conditions gives the following results for the two arbitrary constants:

$$
c_{2}=-\left(c_{1}+\frac{a}{s}+\frac{a}{2 P e^{2}-s}\right)
$$


and

$$
\begin{aligned}
& C_{1}=\frac{a P e e^{-P e}}{2 P e^{2}-s}+\left(\frac{a}{s}+\frac{a}{2 P e^{2}-s}\right)\left(\frac{P e}{2}-\sqrt{\left.\frac{P e^{2}}{4}+s\right) e^{\frac{P e}{2}}-\sqrt{\frac{P e^{2}}{4}+s}}\right. \\
& \left(\frac{P e}{2}+\sqrt{\left.\frac{P e^{2}}{4}+s\right) e^{\frac{P e}{2}} \sqrt{\frac{P e^{2}}{4}+s}-\left(\frac{P e}{2}-\sqrt{\left.\frac{P e^{2}}{4}+s\right)} e^{\frac{P e}{2}}-\sqrt{\frac{P e^{2}}{4}+s}\right.}\right.
\end{aligned}
$$

Because there are no abrupt discontinulties in the functional form for the contaminant source strength, the Stehfest (1970a, 1970b) algorithm was used to numerically invert Eg. 2.50. With this method, the inverse Lapluse transform is obtained using the expression

$$
\bar{L}(t)=\frac{\ln (2)}{t} \sum_{i=1}^{N} V_{i} L\left(\frac{\ln 2 i}{t}\right)
$$

wher" $\mathrm{N}$ determines the accuracy of the approximation (machine-dependent value), and the values for $V_{1}$ are constants dependent on $N$ in the following manner:

$$
v_{i}=(-1)\left(\frac{N}{2}+i\right) \quad \sum_{k=(i+1) / 2}^{\max \left(\frac{N}{2}, i\right)} \frac{k^{\left(\frac{N}{2}+1\right)}\left(\frac{N}{2}-k\right) !(K !)^{2}(i-K) !(2 K-1) !}{(i-k)}
$$

Figures 2.18 and 2.19 show the results of calculations performed for the pumpback geometry and Peclet numbers of 5 and 10, respectively. Concentrations at the quarry pond ( $X=0$, on the plot) are seen to decrease smoothly in time to zero, with higher Pe values producing faster changes in the concentration. Application of the zeroflux boundary condition is also evident by the symmetrical functional form of the concentration at the quarry pond.

The time-dependent behavior of the contaminant concentration for specifled distances is shown in Figures 2.20 and 2.21 for Pe values of 5 and 10, respectively. For all cases examined, the concentration at the quarry pond ( $X=0$, on the plot) monotonically decreases with time to zero. Faster decreases are produced by higher Pe values. 


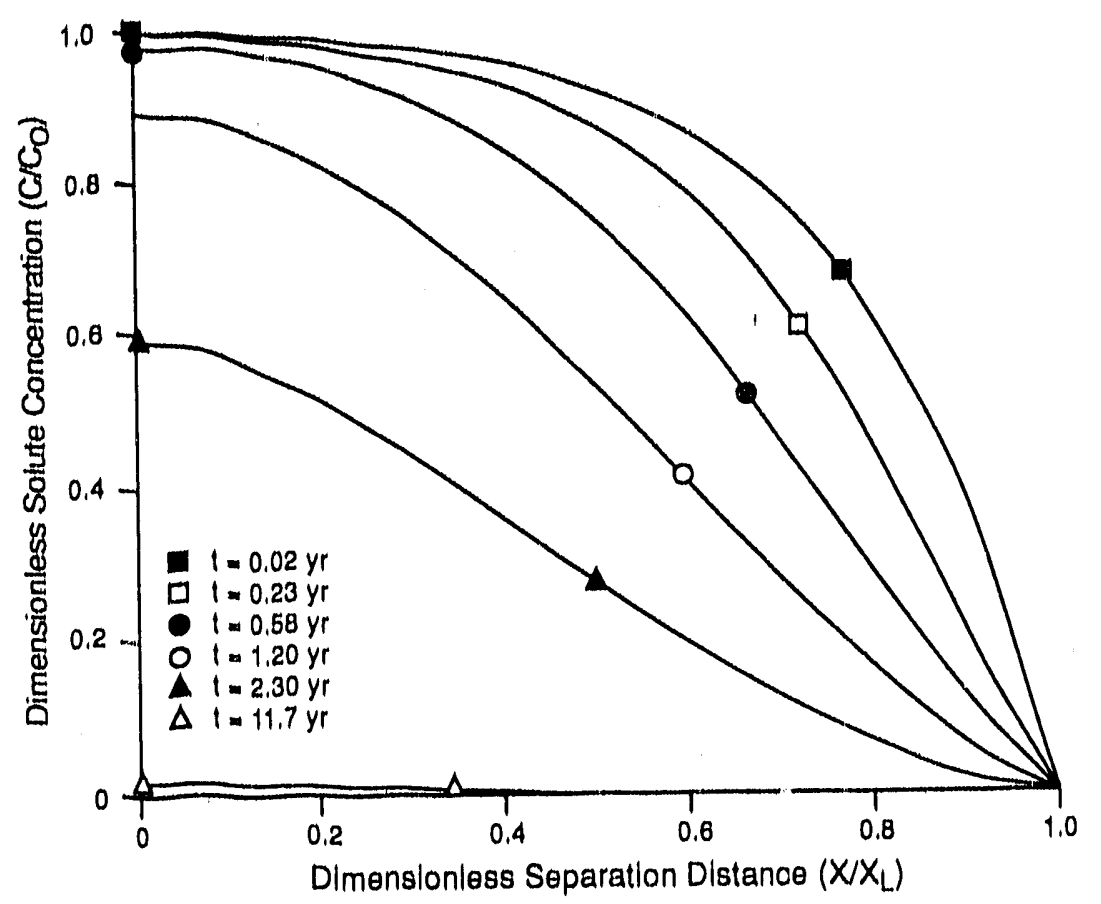

FIGURE 2.18 Pump-Back Concentrations as a Function of Space and Time for $\mathrm{Pe}=5$

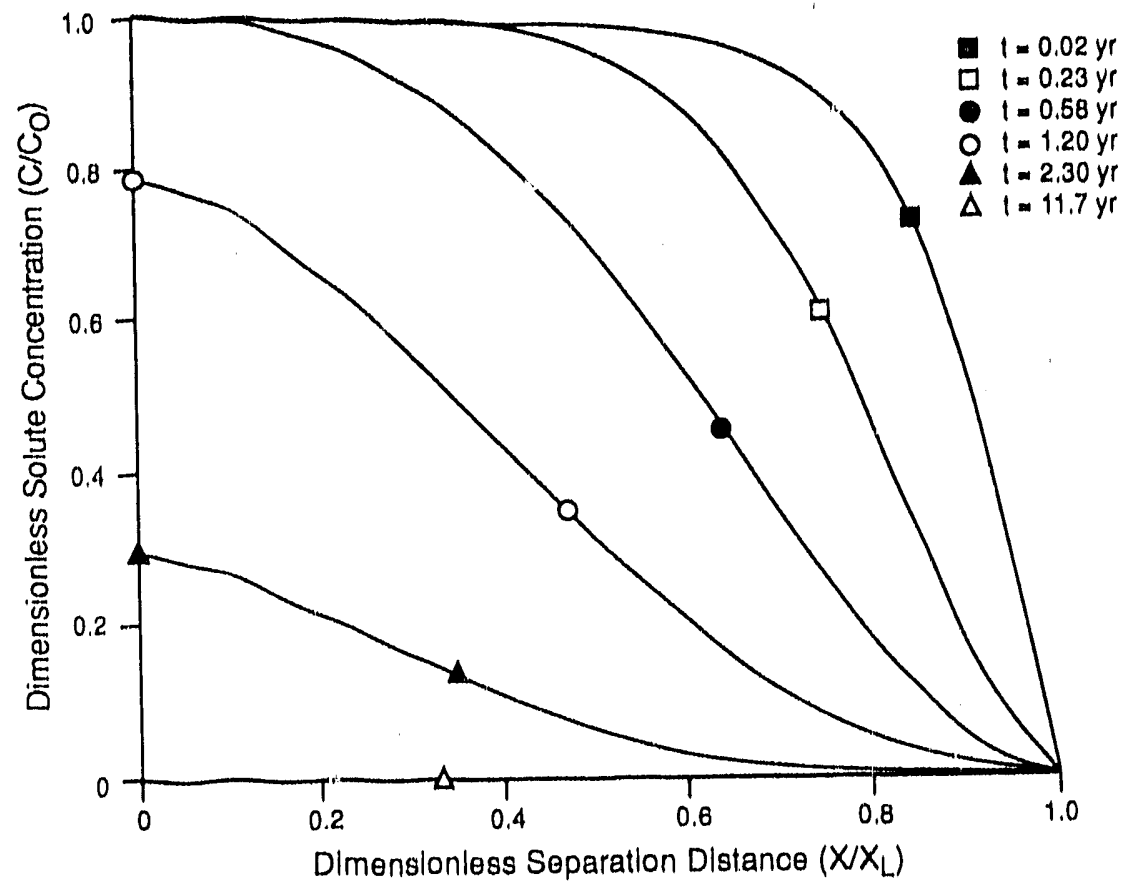

FIGURE 2.19 Pump-Back Concentrations as a Function of Space and Time for $\mathrm{Pe}=10$ 


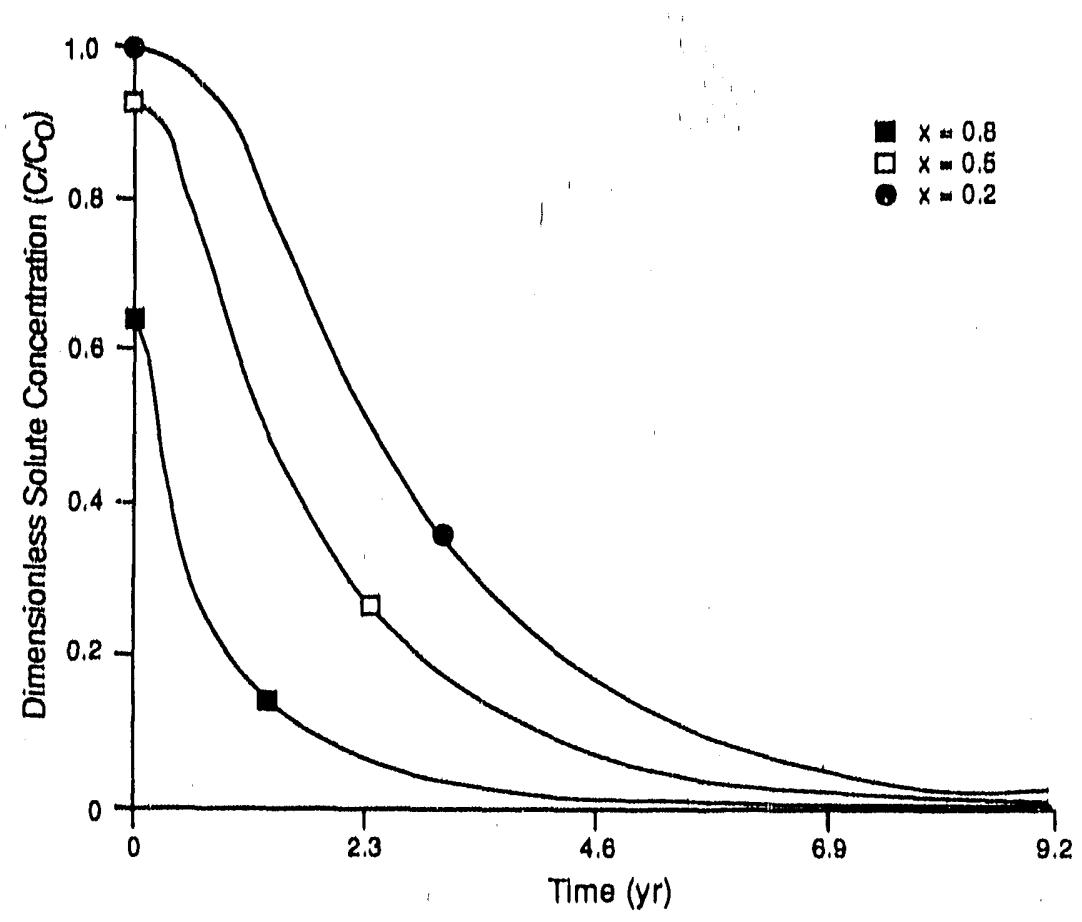

FIGURE 2.20 Pump-Back Concentrations as a Function of Time and Space for $\mathrm{Pe}=5$

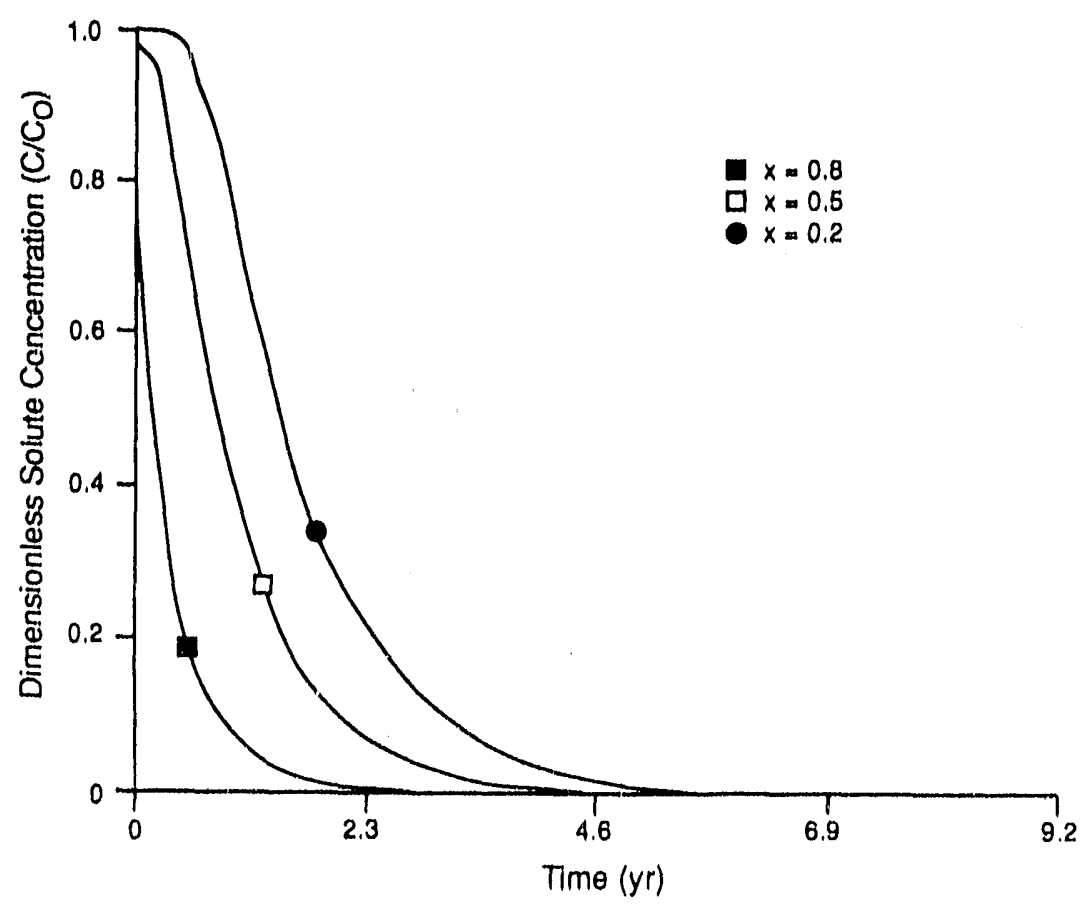

FIGURE 2.21 Pump-Back Concentrations as a Function of Time and Space for $\mathrm{Pe}=10$ 


\section{IMPLICATIONS FOR REMEDIAL-ACTION DESIGNS}

In Sec. 2, analytical expressions were developed to evaluate the effect of a zeroconcentration sink at the Femme Osage Slough on spatial and temporal distributions for a migrating contaminant in a one-dimensional porous medium. In this conceptualization, spatial contaminant concentrations quickly approach a steady-state distribution that is functionally dependent on the flow system's Pe. For lengthy step functions, the spatial concentrations predicted by the finite-sink model are significantly less than those predicted by a model having a zero concentration at infinity, especially near the location of the slough. Fleld measurements in the vicinity of the Weldon Spring quarry for conservative solutes, such as nitrate or sorbing solutes with reversible kinetics, can be used to assist in differentlating the two models and developing an improved conceptual model for the quarry vicinity.

During dewatering of the quarry and bulk-waste removal, pumps will be used to maintain a flow toward the quarry. If assuming a zero-concentration sink at the Femme Osage Slough is appropriate, concentrations measured near the location of the quarry pond should decrease monotonically with time to zero and have relatively flat profiles near the location of the pumps. The actual rate of contaminant concentration decrease will be a function of the advective Pe. However, if the slough does not act as a zeroconcentration sink, concentrations near the location of the pumps may increase with time as the dispersion-broadened slug of contaminant is brought back toward the quarry. With time, higher contaminant concentrations at selected monitoring wells may reflect a returning contaminant slug rather than an increase due to a perturbation in source streng th at the quarry.

Future work entails evaluating existing radionuclide concentration data for the Weldon Spring quarry vicinity to determine the appropriateness of assuming a zeroconcentration boundary at the Femme Osage Slough. 


\section{REFERENCES}

Argonne National Laboratory, 1990, Feasibility Study for Management of the Bulk Wastes at the Weldon Spring Quarry, Weldon Spring, Missouri, DOE/OR/21548-104, prepared by Environmental Assessment and Information Sciences Division, Argonne, Ill., for U.S. Department of Energy, Oak Ridge Operations Office, Weldon Spring Site Remedial Action Project, St. Charles, Mo., Feb.

Bear, J., 1979, Hydraulics of Groundwater, McGraw Hill, New York, p. 567.

Berkeley Ueosciences Associates, 1984, Characterization and Assessment for the Weldon Spring Quarry Low-Level Radioactive Waste Storage Site, prepared for Oak Ridge National Laboratory, Oak Ridge, Tenn., Sept.

Crump, K.S., 1976, Numerical Inversion of Laplace Transforms Using A Fourier Series Approximation, Journal of the Association for Computing Machinery, 23(1):89-96.

Davies, B., and B. Martin, 1979, Numerical Inversion of the Laplace Transform: A Survey and Comparison of Methods, Journal of Computational Physics, 33:1-32.

Ditkin, V.A., and A.P. Prudnikov, 1967, Formulaire Pour Le Calcul Operationnel, Masson et Cie, Editeurs, Paris, France, p. 472.

Dubner, H., and J. Abate, 1968, Numerical Inversion of Laplace Transforms by Relating Them to the Finite Fourier Cosine Transform, Journal of the Association for Computing Machinery, 15(1):115-123.

Freeze, R.A., and J.A. Cherry, 1979, Groundwater, Prentice-Hall, Inc., Englewood Cliffs, N.J., p. 604.

Hilldebrand, F.B., 1976, Advanced Calculus for Applications, Prentice-Hall, Inc., Englewood Cliffs, N.J., p. 733.

Kleeschulte, M.J.» et al., 1986, Hydrologic Data for the Weldon Spring Radioactive Waste-Disposal Sites, St. Charles County, Missouri 1984-1986, U.S. Geological Survey Open File Report 86-488, Rolla, Mo.

Kreyszig, E., 1967, Advanced Engineering Mathematics, John Wiley and Sons, Inc., New York, p. 898.

Lallemand-Barres, A., and P. Pequdecerf, 1978, Recherche des Relations Entre la Valeur de la Dispersivite Macroscopique d'un Milieu Aquifere, Ses Autres Caracteristiques et les Conditions de Mesure, Bulletin Bureau Geologique Minieres, Sec. 3, 4:277-284.

Macdonald, J.R., 1964, Accelerated Convergence, Divergence, Iteration, Extrapolation,

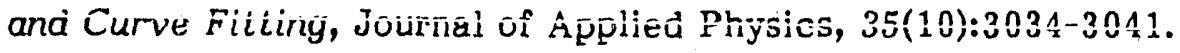


MK-Ferguson Company and Jacobs Engineering Group, 1987, Weldon Spring Site Annual Environmental Monitoring Report, Calendar Year 1987, DOE/OR/21548-015, prepared for U.S. Department of Energy, Oak Ridge Operations Office, Weldon Spring Site Remedial Action Project, Weldon Spring, Mo.

MK-Ferguson Company and Jacobs Engineering Group, 1989, Re nedial Investigations for Quarry Bulk Wastes, DOE/OR/21548-066, Rev. 1, prepared for U.S. Department of Energy, Oak Ridge Operations Office, Weldon Spring Site Remedial Action Project, Weldon Spring, Mo., Dec.

Stehfest, H., 1970a, Algorithm 368, Numerical Inversion of Laplace Transforms, Communications of the Association for Computing Machinery, 13(1):47-49.

Stehfest, H., 1970b, Remark on Algorithm 368, Numerical Inversion of Laplace Transforms, Communications of the Association for Computing Machinery, 13(10):624.

Tomasko, D., 1989, The Effects of a Perturbed Source on Contaminant Transport Near the Weldon Spring Quarry, ANL/EES-TM-370, prepared by Argonne National Laboratory, Energy and Environmental Systems Division, Argonne, Ill., for U.S. Department of Energy, Oak Ridge Operations Office, Oak Ridge, Tenn., March.

Wunsch, A.D., 1983, Complex Variables with Applications, Addison-Wesley Publishing Co., Reading, Mass. p. 439.

Wynn, P., 1956, On A Device for Computing the ${ }^{2} m^{\left(S_{n}\right)}$ Transformation, Mathematical Tables and Other Aids to Computation, 53-56:91-96. 

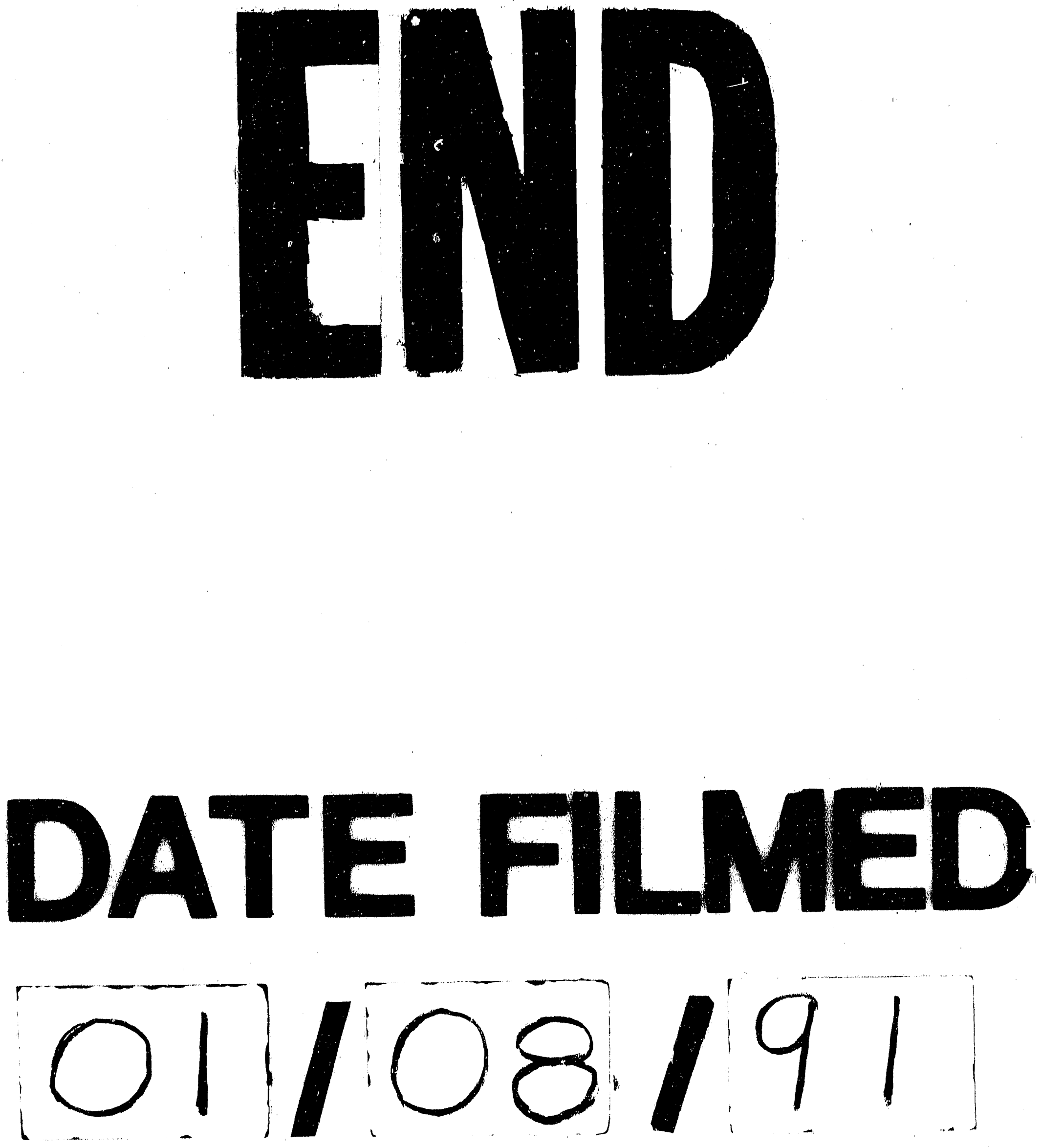
